\title{
Paul Karl Feyerabend: las proyecciones de la proliferación teórica en la relación ciencia-metafísica 1
}

\section{Paul Karl Feyerabend: The Projections of Theoretical Proliferation in the Relation Science-Metaphysics}

\author{
María Teresa GARgiUlo de VAZQuÉZ \\ Universidad de Congreso - Conicet (Argentina)
}

Recibido: 03/02/2014

Aceptado: 13/09/2014

\section{Resumen}

La doctrina de la Proliferación teórica de Paul Karl Feyerabend ha sido interpretada por sus especialistas como un intento de salvaguardar el ideal del progreso científico. Aunque tales estudios hacen justicia, en parte, a la intencionalidad de nuestro filósofo no explicitan la crítica fundamental que implica para Feyerabend el pluralismo teórico. La proliferación teórica constituye en sí misma una reductio ad absurdum de los distintos intentos del positivismo lógico y del racionalismo crítico por definir la ciencia a expensas de lo metafísico. Este artículo presenta la proliferación teórica como una reivindicación del papel positivo que ocupa la metafísica en el quehacer científico. Se consigna la defensa que hace Feyerabend de la metafísica en cuanto que ésta constituye la posibilidad de superar el conservadurismo conceptual, aumentar de contenido empírico de la ciencia y recuperar el valor descriptivo de las teorías científicas.

Palabras claves: Ciencia, ciencia-metafísica, Feyerabend, Positivismo lógico, proliferación teórica, racionalismo crítico.

\footnotetext{
1 Agradezco a los réferis anónimos las observaciones formuladas a la primera versión de este trabajo.
} 


\begin{abstract}
The Paul Karl Feyerabend's doctrine of theoretical proliferation has been interpreted by his experts as an attempt to preserve the ideal of scientific progress. This hermeneutics describes, in part, the intention of our philosopher. However, this reading does not explain the fundamental criticism that theoretical pluralism supposes for Feyerabend. The theoretical proliferation is itself a reductio ad absurdum of the attempts of logical positivism and critical rationalism to define science at the expense of the metaphysical. This article presents the theoretical proliferation as a vindication of the positive role that the metaphysical plays in scientific practice. We expose the Feyerabend's defense of metaphysics inasmuch as it is constitute the possibility to overcome the conceptual conservatism, to increase empirical content of science and to recover the descriptive value of scientific theories.
\end{abstract}

Keywords: Critical rationalism, science, science-metaphysics, Feyerabend, logical positivism, theoretical proliferation.

\title{
1. Introducción
}

En el pluralismo metodológico Feyerabend expone la necesidad de examinar racionalmente los supuestos ontológicos que atraviesan las teorías científicas en orden a evitar que éstos degeneren en dogmas que imposibiliten el progreso científico. El progreso científico, tal como es definido por el positivismo lógico y el racionalismo crítico, es posible -argumenta el vienés- en cuanto que la filosofía no se limita a reflejar los desarrollos de la ciencia sino en la medida que juega un rol activo y crítico en la ciencia, construyendo visiones del mundo alternativas a las imperantes, y superando así toda clase de dogmatismos.

La bibliografía especializada en torno a Feyerabend ha destacado que en su pluralismo metodológico el objetivo de la filosofía es contribuir al progreso científico impidiendo que los supuestos ontológicos de las teorías científicas se constituyan en dogmas (Cf. Oberheim, 2006, p. 284; Oberheim, Hoyningen-Huene, 2000, pp. 373-376; Preston, 1997a, pp. 74-79; 1999, p. 235; Farrell, 2003), pp. 96-97; Reaven, 2000), p. 23; Couvalis, 1999, pp. 215-216; Munévar 1999, pp. 225-226; Sirtres, Oberheim 2006, p. 1148). No obstante, en tales estudios no se advierte, ni se subraya suficientemente, las implicancias que tiene su inicial pluralismo metodológico -y, más tarde, su pluralismo teórico- en su nuevo modo de entender la ciencia respecto a la metafísica. Aquellas lecturas no dan cuenta de la intencionalidad última del vienés respecto de su proliferación teórica $\mathrm{y}$, en consecuencia, son impotentes para comprender la repercusión que éste tiene en el tratamiento de la 
relación entre ciencia y metafísica como una parte integral y cada vez más fundamental de la comprensión que Feyerabend tiene de la ciencia. Nuestro filósofo vienés no se limita a elaborar una metodología que preserve a la práctica científica del establecimiento de dogmas sino que busca fundamentalmente elaborar un modelo de racionalidad donde la metafísica se le presenta como condición de una verdadera ciencia.

En un contexto de cuestionamientos radicales a lo que se reconoce como la Concepción Heredada Feyerabend se aboca a demostrar las contradicciones y limitaciones que suponen tanto los intentos del neo-positivismo lógico como los del racionalismo crítico por establecer un criterio de demarcación. Ya sea que se conciba el principio de demarcación como un criterio lógico-formal o metodológico Feyerabend asegura que en ambos casos se trata de un criterio vacío.

A través de tres cuestiones Feyerabend demuestra esta tesis, a saber, por medio de su crítica al modelo positivista del significado, de su doctrina de la inconmensurabilidad con su respectiva propuesta de un pluralismo teórico y a través de su anarquismo epistemológico. Estos constituyen los distintos focos de discusión o crítica a partir de los cuales el vienés reduce al absurdo los distintos intentos de establecer un criterio de demarcación.

El presente artículo expone particularmente el lugar que la metafísica ocupa en su proliferación teórica. Se presenta su valoración positiva de la metafísica en el quehacer científico en cuanto que ésta previene los dogmatismos que obstaculizan el progreso científico (1), aumenta el contenido empírico de las teorías científicas (2), y permite superar el carácter instrumental que presentan ciertas teorías (3).

\section{La tesis de la Proliferación Teórica como superadora del conservadurismo conceptual}

Feyerabend desde una metafísica neokantiana rechaza cualquier forma de necesidad trascendental. Su pluralismo teórico excluye toda perspectiva externa privilegiada en la medida que ella supone un conservadurismo conceptual. El conservadurismo conceptual puede entenderse como el intento de conservar en las transiciones teóricas los resultados, la base observacional y la estructura lógica de la teoría anterior.

Eric Oberheim (2005) demuestra cómo Feyerabend utiliza su doctrina de la inconmensurabilidad para objetar el conservadurismo conceptual implícito en el uso de las oraciones protocolares del positivismo lógico, en el principio metodológico de Heisenberg, en la teoría de la teoría de la reducción de Nagel y en la teoría de la explicación de Hempel y Oppenhein.

Pero sin duda, y aunque Oberheim no se ocupe de ello, fue el principio de complementariedad de Niels Bohr lo que constituye el blanco principal de las críticas 
que Feyerabend dirige contra el conservadurismo conceptual. Uno de los supuestos ontológicos sobre los que se funda el principio de complementariedad -según el vienés - dicta que todo resultado experimental o conocimiento no puede ser sino expresado en los términos de la física clásica (Cf. Feyerabend, 1958/1981a, pp. 22$23)^{2}$. Las categorías propias de la física clásica para Bohr influyen de tal modo en los procedimientos experimentales y aún en las formas de percepción que es imposible imaginar una alternativa diferente para explicar los fenómenos físicos. El hombre parecería estar -según el físico- determinado a aprehender la evidencia tal como lo postula la física clásica (CF. Bohr 1928).

El vienés objeta a Bohr que esta imposibilidad de encontrar un nuevo esquema conceptual no ha sido demostrada por la misma física, sino que se apoya en el sólo hecho de que tal esquema no-clásico estaría en conflicto con su conciencia positivista. Los límites de la capacidad humana no se deben ni a falta de imaginación, ni a un límite en las habilidades de los físicos que les impida ir más allá de las ideas clásicas, sino a una decisión metafísica más o menos consciente de no ir más allá de la experiencia que dispone la física clásica (Feyerabend, 1958a, pp. 80-87).

La defensa de la tesis de Feyerabend a favor de la utilidad de la metafísica para favorecer la proliferación teórica y evitar el conservadurismo conceptual opera con el supuesto implícito de que, evitadas las contradicciones lógicas, la mente humana estaría capacitada para pensar el mundo de cualquier forma, esto es, bajo cualquier esquema conceptual. La capacidad del hombre para crear conceptos o teorías es infinita. Nuestro filósofo de la ciencia (1958/1981a, p. 24) sostiene que incluso en el caso de que una situación observacional parezca sugerir una única interpretación o teoría como universalmente verdadera, es posible inventar un nuevo proyecto conceptual, en la medida que se dispongan de nuevas imágenes metafísicas del mundo. Nada puede limitar esta libertad de interpretación -afirma-, excepto las mismas restricciones que impone la ontología o tradición que se elija (Feyerabend, 1962/1989, p. 56).

La exclusividad que Bohr concede a las formas perceptivas clásicas se puede entender para Feyerabend (1958/1981a, p. 24) en virtud de su adopción de una metafísica positivista y de una teoría pragmática de significado.

El positivismo postula que sólo podemos inventar aquellas teorías que son sugeridas por las observaciones. Ahora bien, las formas de percepción, los modos de aprehender la experiencia, según el físico, son clásicos. Luego, no disponemos, según él, de otro modelo intuitivo, de otro modo de visualizar la experiencia sino es

\footnotetext{
2 Para facilitar la lectura, las citas de las obras de Paul Feyerabend tendrán doble fecha. La primera se refiere al año de la primera publicación y la segunda a la publicación consultada. El objetivo de la doble fecha es dar cuenta de un orden cronológico de las publicaciones y, al mismo tiempo, remitir al lector a los lugares precisos donde pueda cotejar las citas textuales, las paráfrasis y las referencias generales.
} 
en los términos propios de la física clásica. Por tanto, una imagen no clásica de los fenómenos subatómicos sería - desde esta concepción metafísica- psicológicamente imposible (Cf. Feyerabend, 1962/1981a, p. 320)33.

Según la teoría pragmática la significación de un término o una expresión está determinada por su uso. Ahora, el esquema conceptual empleado habitualmente para la explicación y predicción de los hechos son los propios de la física clásica. La física clásica es un esquema conceptual universal donde ningún hecho puede quedar fuera de su dominio de aplicación. Ésta determina el lenguaje, las experimentaciones e incluso las formas de percepción. Luego, en el marco de una teoría pragmática de significado la invención de un nuevo aparato conceptual no-clásico, se presenta, además de psicológicamente imposible, como lógicamente absurda (Cf. Feyerabend, 1958/1981a, pp. 21-23).

Nuestro epistemólogo (1962/1981a) insiste que la imposibilidad que ve Bohr para crear imágenes no clásicas es de carácter lógico y no sociológico; y esto lo hace en oposición a Heisenberg y von Weizsaecker, quienes afirman que introducir conceptos no clásicos sería prácticamente imposible debido a la costumbre de la mayoría de los físicos contemporáneos de utilizar el lenguaje de la física clásica como lenguaje observacional.

Bohr niega que alguna vez sea posible inventar una teoría universal que trascienda el ámbito clásico y que es erróneo creer que las dificultades de la teoría atómica podrían ser superadas remplazando eventualmente los conceptos de la física clásica por nuevas formas conceptuales (Cf. Feyerabend, 1958a, p. 85). Es en estas afirmaciones de Bohr donde el vienés entrevé el peligro de que las teorías o principios se constituyan en dogmatismos irrefutables. Feyerabend (1960/1981a, pp. 221223) confiesa que la lectura de Causality and Chance in Modem Physics de Bohm (1957), le enseñó que los argumentos y justificaciones que ofrece Bohr son insuficientes para fundamentar la validez de su principio. Bohr formula argumentaciones circulares en cuanto que no considera ningún hecho o evidencia fuera del dominio de la aplicación de su principio. Desde él se moldea y organiza de tal modo la evidencia que no existen hechos que sean capaces de cuestionarlo o de sugerir una nueva teoría. De aquí que ni la experiencia, ni el formalismo matemático serán suficientes -explica Feyerabend- para elegir entre éste y otra teoría empíricamente exi-

\footnotetext{
3 El epistemólogo (1958a, pp. 81-82) ubica la filosofía de Bohr dentro un tipo específico de positivismo. Por un lado, el epistemólogo advierte que el físico se aleja de la concepción positivista habitual según la cual las experiencias sensibles por sí mismas no poseen ninguna propiedad formal; éstas consistirían en simples elementos desorganizados, tales como las sensaciones de color, de tacto, etc. Bohr, en cambio, insiste que las experiencias están organizadas por las categorías o formas de percepción de la física clásica y que no pueden existir sin estas formas. La experiencia no puede ser organizada y explicada por otras formas de percepción o categorías que no sean las propias de la física clásica. Este carácter insustituible que concede a las nociones clásicas hace que, según Feyerabend, Bohr permanezca dentro de un tipo específico de positivismo.
} 
tosa. El principio de complementariedad se le presenta al vienés como una posición metafísica inmune a todo tipo de refutación 4 .

En otra ocasión Feyerabend utiliza ya la noción de inconmensurabilidad -aunque no el término mismo- para criticar el conservadurismo conceptual del físico. Postula que podrían ser inventados conceptos completamente nuevos e incompatibles (o inconmensurables) con los conceptos clásicos siempre que existan imágenes abstractas del mundo o metafísicas que pueden convertirse en auténticas teorías físicas.

Bohr, en cuanto exige que la conducta de los fenómenos cuánticos sea expresada necesariamente en los términos propios de la física clásica, impide el desarrollo de nuevos términos obstaculizando el progreso científico (Cf. Feyerabend, 1958a, p. 81.). El epistemólogo ilustra esta tesis mostrando que en la transición de la concepción física de Aristóteles a la de Galileo surgen términos o nociones que no son meras derivaciones o modificaciones de las nociones anteriores; se trata de categorías completamente nuevas que no guardan relación lógica alguna con las categorías que la anteceden. Pues bien, él sostiene que de modo análogo los conceptos propios de la física clásica también podrían ser remplazados por un nuevo esquema conceptual. Después de todo, -agrega- la distancia que existe entre un esquema conceptual clásico y uno no clásico no es mayor que la distancia que existió entre la concepción física de Aristóteles y la de Galileo (Feyerabend, 1962/1981a, pp. 323-325).

Aquí podría decirse que Feyerabend incurre en una petición de principio. A saber da por demostrado que la distancia que existe entre un esquema conceptual clásico y uno no clásico es menor a la que existe entre la física ptolemaica y la copernicana. Pero ¿cómo puede él saber si esa distancia no es mayor si al mismo tiempo denuncia que aún no disponemos de un esquema conceptual no clásico? Esta aparente poca distancia entre estos distintos esquemas conceptuales no demuestra su tesis acerca de la posibilidad real de acceder a categorías no clásicas mediante la especulación metafísica sino que la supone en sus premisas.

\footnotetext{
${ }^{4}$ Más tarde, Feyerabend (1968/1981), pp. 273-281) atenúa su posición y presenta el principio de complementariedad no como un dogmatismo filosófico sino más bien como una hipótesis física. Afirma que Bohr era consciente del carácter meramente instrumental del principio de complementariedad y que estaba dispuesto a admitir la necesidad de nuevas teorías alternativas que permitieran un entendimiento más profundo del comportamiento cuántico. Explica que Bohr tenía algunas razones filosóficas - provistas por una metafísica materialista- para esperar que esta hipótesis sea verdadera. Pero esta filosofía no le impidió al físico explorar otras alternativas. Fue justamente la consideración y refutación de estas alternativas -tal como el epistemólogo muestra en la sección 5 de este artículo- lo que lo condujo a sus ideas originales y lo convenció de la corrección y validez de su perspectiva filosófica. Para Feyerabend la consideración de otras alternativas libera a Bohr del peligro de convertir el principio de complementariedad en una "inarticulada fe filosófica".

A pesar de estas retractaciones por parte de Feyerabend, aquella primera acusación que hizo a Bohr de mantener una actitud dogmática le permitió entender la necesidad de una proliferación teórica en cuanto que esta permitiría evitar que el quehacer científico se vea obstaculizado por la aceptación acrítica de ciertos dogmas metafísicos.
} 
Ahora bien, Feyerabend (1965/1981b, pp. 107-108) advierte que estas nuevas interpretaciones o teorías alternativas no pueden emerger de la cerrada atención a los 'hechos'. Pues en una teoría siempre existe el peligro de que se seleccionen sólo aquellos datos o resultados que la confirman y se rechacen simultáneamente todos aquellos que no puedan acomodarse a ella. Una teoría científica puede disponer la evidencia empírica de tal modo que su punto de vista quede reforzado y constituirse así en una verdad absoluta con un pobre contenido empírico.

Se sigue entonces la necesidad de una fuente no-observacional para tales interpretaciones. Tal fuente es provista según el vienés (1958/1981a, p. 31) por la especulación metafísica. Ésta otorga al científico de la libertad necesaria para crear nuevos conceptos los cuales develarían, en este caso, que el carácter absoluto y definitivo concedido al principio de complementariedad no es más que un dogmatismo que entorpece el progreso de las teorías microscópicas.

\section{La Doctrina de la Proliferación Teórica como posibilidad de aumentar el contenido empírico}

Feyerabend (1961a, p. 402) define el contenido empírico como la posibilidad que tiene una teoría de ser empíricamente testeada. Una teoría tiene contenido empírico solo si ésta es comprobable o falsable -afirma el vienés tratando de abarcar con tal definición tanto la visión de Popper (1980) como la de Carnap (1978) al respecto-.

Popper distingue dos tipos de sentencias básicas lógicamente posibles:

[...] la clase de todas aquellas sentencias básicas con las cuales algo es inconsistente (o que éstas excluyen, o prohíben): llamamos a esto la clase de falsadores potenciales de la teoría; y en segundo lugar, la clase de todas aquellas sentencias básicas con las cuales algo no se contradice (o que éstas 'permiten') (Popper, 1980, p. 86).

Para Popper aquellas sentencias que establecen falsaciones potenciales de una teoría constituyen el contenido empírico de una teoría. Es necesario destacar que Popper no concede a las sentencias básicas un carácter fundacional o indubitable. Por el contrario, sostiene que todos los términos son teóricos aunque algunos son más teóricos que otros (Popper, 1972, p. 388). Esto implica que las sentencias observacionales que componen la base empírica deben ser teóricas, singulares, relativas a hechos observables y, por ende, objetos de falsaciones intersubjetivas (Cf. Popper, 1980, pp. 44) 5 .

\footnotetext{
5 Es pertinente esta precisión ante la confusión de Laudan (1996) y Worrall (1978) quienes acusan a Feyerabend de incoherente debido a una errónea comprensión que ellos mismos poseen acerca de lo
} 
Feyerabend asume esta concepción y el principio de aumento de contenido según el cual una teoría es preferible en cuanto ofrece mayor información que las teorías precedentes. Pero no lo hace en orden a defender positivamente esta concepción o principio, o para proponer una nueva visión como sugiere Preston (1997a, pp. 133-134). Lo que pretende demostrar, por reducción al absurdo, es la paradoja por la cual el principio de aumento de contenido exige tanto al popperiano como al positivista adoptar la proliferación teórica y, por ende, ser un buen metafísico.

El argumento extraído de la ciencia dice que la proliferación se desprende de la exigencia de un alto contenido empírico que el propio científico se autoimpone (TCM, pp. 24-25 y 31). Yo no acepto la exigencia, que es sólo una de las muchas formas de organizar nuestras creencias (ibíd., p. 193) y, por lo tanto, no defiendo sus implicaciones; lo que digo es que los científicos que están a favor de un alto contenido empírico están también a favor de la proliferación y no pueden, por consiguiente, rechazarla (Feyerabend, 1978/ 1982, p. 169)6.

John Preston (1997a) y Ronald Laymon (1977) acusan paradójicamente a Feyerabend de positivista en cuanto que el único criterio que ofrece para elegir entre teorías alternativas es el aumento de contenido empírico, ideal propio del positivismo lógico. Nélida Gentile (2007) formula un razonamiento análogo argumentando que los ideales del positivismo parecen animar tanto su realismo conjetural como su pluralismo metodológico. Probablemente la confusión de Preston, Laymon y Gentile se debe a desconocer uno de los recursos habituales que emplea Feyerabend para mostrar la inconsistencia de la tesis que ataca, es decir, su uso de los razonamientos por reducción al absurdo. El vienés asume el ideal del positivismo, a saber, el aumento de contenido de la ciencia, pero no porque esté comprometido con él, sino en orden llevar a cabo una crítica inmanente al positivismo que podríamos formular del siguiente modo: no se puede sostener un positivismo y, al mismo tiempo, el principio de aumento de contenido. Si Popper o un empirista pretende aumentar el contenido de la ciencia, entonces debería estar dispuesto a revalorizar la metafí-

\footnotetext{
que es para Popper el contenido empírico. Ambos cuestionan a Feyerabend si toda teoría va a ser inconsistente con una teoría por el solo hecho de poseer consecuencias empíricas contrarias. Uno y otro entienden el contenido empírico o los falsadores potenciales como la negación de las consecuencias empíricas de una teoría. Pero tal definición es falsa. Para Popper aquellas sentencias que niegan el contenido empírico de una teoría no constituyen en sí mismas falsadores potenciales. Para ello, es necesario además que las sentencias básicas cumplan además los requisitos que se explicitan arriba. 6 Feyerabend insiste que desde las categorías del racionalismo crítico y del positivismo lógico no se puede hablar propiamente de progreso científico. Éstos deben reconocer que solo hay cambios o una sucesión de teorías, tradiciones o paradigmas mutuamente inconmensurables (Cf. Feyerabend, 1958/1981a, p. 29 y ss.; 1958a, pp. 81-83; 1958/1981b, p. 240, n. 6; 1960/1981b, p. 219; 1961b, pp. $246-247 ; 1961 / 1999$, p. $70 ; 1962 / 1981$ b, pp. 83 y $88 ; 1962 ; 1963 / 1999$, pp. 83 y ss.; 1965 , pp. 170 у 199; 1965/1981b, pp. 107 y 110; 1967, p. 117).
} 
sica como fuente y posibilidad de concretar un pluralismo teórico y, por tanto, a integrarla como elemento esencial del quehacer científico.

Feyerabend señala que un buen empirista debe desarrollar explicaciones alternativas de las situaciones experimentales que validan una teoría imperante. Pues sólo en el marco de nuevas teorías es posible que las mismas situaciones experimentales u otras nuevas develen un potencial refutador de la teoría vigente. Es posible obtener nueva evidencia empírica, capaz de refutar una teoría firmemente arraigada, en la medida que se proponen y desarrollan nuevas teorías alternativas. Luego la adecuación fáctica de una teoría con la experiencia solo puede ser asegurada después que ésta ha sido confrontada con teorías alternativas. Feyerabend escribe que,

[...] de acuerdo a sus propias explicaciones [las de Popper y del positivismo] la invención de teorías alternativas a la visión que permanece en el centro de las discusiones constituye una parte esencial del método empírico (Feyerabend, 1965/1981b, pp. 105106).

Tanto un positivista como un racionalista -según el vienés- deben estar dispuestos a trabajar con teorías alternativas antes que con un único punto de vista y la 'experiencia'. Feyerabend presenta así la proliferación teórica como el método que satisface las exigencias de comprobación o de falsación teórica:

También trataré de dar una metodología positiva para las ciencias empíricas que no aliente la petrificación dogmática en nombre de la experiencia. Puesto en una cáscara de nuez, la respuesta que este método da a la pregunta del título es: usted puede ser un buen empirista sólo si usted está preparado para trabajar con muchas teorías alternativas antes que con un único punto de vista 'y la experiencia'. Esta pluralidad de teorías no debe ser considerada como una etapa preliminar de conocimiento que va a ser substituida en el futuro por una única Teoría Verdadera. El pluralismo teórico es asumido como un rasgo esencial de todo el conocimiento que reclama ser objetivo (Feyerabend, 1963/1999, p. 80).

Podría objetarse a Feyerabend que Popper no descarta en absoluto la tesis de la proliferación. En el capítulo 10 de la primera edición de sus Conjeturas y Refutaciones ya Popper (1963, pp. 283-287) argumentaba que el pluralismo teórico es absolutamente consustancial a la idea de comparación de teorías por su verosimilitud. Ciertamente aquí Popper se refiere a la comparación de teorías de dos en dos. Pero evidentemente nada impide que se pueda establecer una cadena de verosimilitudes entre varias teorías competidoras. Ahora bien, si el pluralismo teórico es un constitutivo esencial de la filosofía popperiana, si Popper reconoce la importancia metodológica de la proliferación teórica para el progreso científico, ¿qué es lo que entonces Feyerabend le objeta? ¿Qué tesis de Popper está intentando de reducir al absurdo? 
Al que supo ser su supervisor en la London School of Economics, el vienés le señala que si reconoce la importancia metodológica de introducir teorías alternativas para el progreso científico, entonces también tiene que estar dispuesto a abandonar su criterio de demarcación entre ciencia y metafísica. Popper -según el vienés- debería dejar de considerar la metafísica como un elemento pre-científico para reconocerla como el gozne central donde se resuelve el entero curso de la actividad científica. Para dar cuenta de ello Feyerabend muestra cómo aquellos elementos frente a los cuales se procura delimitar una definición negativa de ciencia, constituyen paradojalmente el seno del quehacer científico. En este caso, particularmente argumenta el papel central que juegan los elementos metafísicos en el progreso científico. Muestra que lo que el racionalista reconoce como metafísica no se comporta simplemente como un reservorio imaginativo pre-científico que puede constituir la génesis de nuevos modelos explicativos. Sino que estos elementos metafísicos son, sobre todo, metodológicamente imprescindibles para llevar a cabo la tarea característica de la racionalidad científica, a saber, la revisión crítica de las teorías científicas.

Para Popper (1985, pp. 194-195) el aumento del conocimiento, es decir el progreso científico depende fundamentalmente de la revisión crítica de las teorías. Ahora bien, Feyerabend le señala que esta revisión crítica solo puede ser llevada a cabo mediante la introducción de teorías alternativas que son, en sus inicios, auténticos sistemas metafísicos. Luego debe reconocer que el mismo progreso científico nos exige ser buenos metafísicos, y por tanto abandonar su distinción entre los elementos pre-científicos y científicos.

$\mathrm{Al}$ destacar la presencia de la metafísica en la ciencia Feyerabend no pretende denostar la ciencia sino demostrar que es falsa la dialéctica que el racionalista crítico establece entre ciencia y metafísica. En un sentido positivo, se puede decir que el vienés concibe la ciencia como un conjunto de múltiples e incluso antagónicas tradiciones y desde ella cuestiona la noción univoca de racionalidad científica que postula el racionalismo crítico.

En orden a definir dialécticamente la ciencia respecto a lo no científico Popper destaca la crítica como el elemento racional y distintivo del progreso científico. Para él el método de la ciencia se basa esencialmente en la crítica:

[...] las teorías científicas se distinguen de los mitos simplemente en que pueden criticarse y en que están abiertas a modificación a la luz de las críticas. No pueden verificarse ni probabílifícarse. (Popper, 1985, 47).

Popper no concibe a la ciencia como algo esencialmente distinto de los antiguos mitos. Por el contrario, asegura que la ciencia contiene en sí misma una visión del mundo y suposiciones metafísicas características del pensamiento mítico. La ciencia se distingue del mito en cuanto que es acompañada por una tradición de segun- 
do orden, es decir, por la discusión crítica de sus elementos míticos. Popper (1966, 231) admite además que pueden descubrirse, inventarse, aceptarse e impartirse a otras personas de manera muy irracional nuevos estándares. Señala, sin embargo, que uno puede criticarlos después de que han sido adoptados, y que esta posibilidad es lo que garantiza la racionalidad del conocimiento científico.

Contra esto, en primer lugar, Feyerabend (1991a, 140) objeta que muchas de estas conjeturas o suposiciones metafísicas que atraviesan la ciencia nunca se constituyen en objeto de una discusión explícita. Simplemente son parte de un proceso general de adaptación de las teorías científicas que implica las relaciones reales entre colegas, las restricciones financieras, las limitaciones de tiempo y el devenir de formalismos matemáticos y académicos. En segundo lugar, le señala que tal definición de ciencia incurre en una petición de principio pues si todo elemento científico debe someterse a una discusión crítica entonces también esta misma noción de ciencia debería ser sometida a un análisis crítico:

Lo que llamamos "ciencia" escribe Popper 'se diferencia de los mitos más antiguos no por ser algo diferente de un mito' -no deja de contener una 'visión del mundo' y supuestos 'conceptuales' característicos del pensamiento mítico- 'pero que al ser acompañada por una tradición de segundo orden -la de discutir críticamente el mito: la ciencia una es visión del mundo, etc., más el modelo de resolución de problemas. Popper trata en consecuencia los problemas conceptuales de la ciencia temprana, muestra cómo el modelo de resolución de problemas trata cuestiones no empíricas (teorías metafísicas, aunque irrefutables, pueden ser evaluadas mediante la comparación de sus capacidades de resolución de problemas), critica los físicos modernos por no considerar seriamente los problemas conceptuales y él mismo propone soluciones para ellos. Es cierto que los popperianos han combinado el modelo de resolución de problemas con la verdad, la verosimilitud y la corroboración y, más recientemente, lo han casi enterrado bajo estas ideas, pero esto no menoscaba la utilidad del propio modelo para que pueda ser discutido y desarrollado 'sin hablar de la verdad de sus teorías' (Feyerabend 1981c, 234-235. TN).

Bartley $(1964,30)$ adjudica a Popper un racionalismo comprensivamente crítico (CCR) según el cual debe ser consecuente con su falsacionismo y someter a crítica a todas sus creencias, estándares e incluso a sus posiciones filosóficas básicas. Podría argumentarse contra Bartley -y en este caso también contra Feyerabendque Popper (1966, 232-240) no sostiene este tipo de racionalismo; más bien lo postula como una decisión convencional de carácter ético ${ }^{7}$. No obstante, la argumentación por reducción al absurdo que lleva a cabo Feyerabend es independientemente de si Bartley con su noción de CCR captura la intencionalidad del racionalismo popperiano, o de las paradojas lógicas autorreferenciales que surgen en torno a esta noción de racionalismo (Cf. Radnitzky, Bartley 1987). Feyerabend (1963/1999, 80-

\footnotetext{
7 Para una exposición del debate entre Bartley y Popper se puede ver, Gattei 2002, 240-266.
} 
81; 1964a, 253-254; 1968/1999, 107-108; 1970/1989, 99-100; 1972/1999, 174175 ; 1975/1992, 47-48, 130-131, 138-140, 143-144, 158-161; 1980/1999, 212-214; $1991 b, 77)$ reiteradamente demuestra en su pluralismo teórico que la noción crítica de ciencia postulada por Popper únicamente es posible en los términos de una yuxtaposición de teorías alternativas que tienen de suyo una naturaleza metafísica ${ }^{8}$. Ahora bien, tales teorías metafísicas inicialmente no son susceptibles de ser falsadas. Luego, esta proliferación teórica exige obviar la falsación como criterio de demarcación. En este sentido, Feyerabend denuncia que el criterio de demarcación que ofrece Popper no define el quehacer científico real. Lo único que permite es establecer si una investigación o teoría científica se somete o no a su metodología falsacionista. El epistemólogo vienés escribe "lo que llamas ‘la teoría de Popper' es una contribución a la teoría de las confirmaciones y que no tiene nada que ver con la ciencia" (Feyerabend, 1989/2000, p. 61).

En pocas palabras, Popper puede llegar a reconocer la importancia metodológica de la proliferación teórica pero seguramente no estaría dispuesto a reconocer -tal como hace Feyerabend- a las teorías alternativas como metafísicas. Y mucho menos quizás, a admitirle al vienes el fracaso de su criterio de demarcación.

Para nuestro epistemólogo, las teorías alternativas ofrecen explicaciones, que al no estar originariamente vinculadas con la observación, deben ser reconocidas como metafísicas. Para Feyerabend no toda teoría tiene el rango de una teoría alternativa. Una teoría posee el rango de teoría alternativa en la medida que ofrece una explicación de todo lo real y pueda remplazar a su teoría rival como un todo. No constituyen teorías alternativas aquellas que significan solo una crítica parcial de la teoría imperante (Cf. Feyerabend, 1958a, pp. 78-79, 90-91; 1961/1999, pp. 52-54; 1962/1981a), p. 323; 1962/1989, pp. 38, 137-138; 1965/1981b, pp. 109-110; 1975/1992), pp. 102-103). El vienés (1965, p. 214) sugiere, además, que las teorías alternativas más eficientes son aquellas que difieren ontológica y radicalmente del punto de vista a ser investigado. De aquí que la defensa que hace de la proliferación teórica implica reivindicar simultáneamente a la metafísica

Los sistemas metafísicos se le presentan a Feyerabend como teorías científicas en su estado más primitivo que al contradecir resultados observacionales o teorías altamente confirmadas permiten llevar a cabo una crítica a aquellas teorías que se autoproclaman como consistentes en nombre de la experiencia. El rechazo -característico del empirismo lógico- a todo tipo de especulación no conduce a una actitud más crítica. Por el contrario, entroniza por sí mismo -según el vienés- nuevas autoridades tales como la experimentación empírica. Si se excluyera de la ciencia

\footnotetext{
8 Feyerabend destaca que la proliferación teórica no solo reguarda los ideales críticos del modelo de ciencia popperiano sino también, y sobre todo, sus compromisos éticos (Cf. Feyerabend 1961/1999, 69-70, 77; 1970/1981a, 65-67; 1970/1981b, 143-144; 1970/1989, 24-25; 1975/1992, 4-6; 1976, 387$388 ; 1978 / 1982,158-159,200 ; 1978 / 1993,182-186 ; 1996 / 1999,79-80)$.
} 
toda especulación metafísica -explica el epistemólogo- no solo disminuiría el contenido empírico de la ciencia sino que además las teorías científicas devendrían en dogmatismos o mitos.

Para el vienés (1961/1999, pp. 50-77) los mitos están construidos de tal modo que son confirmados por todas las experiencias posibles 9 . Proteger la ciencia de toda refutación potencial implica para él el fin de la ciencia como empresa racional. De aquí que Feyerabend concluya el citado artículo sosteniendo que un buen empirista debe ser un metafísico crítico:

Un buen empirista no descansará contento con la teoría que está en el centro de atención y con aquellas pruebas de la teoría que pueden ser realizadas de una manera directa. Sabiendo que las críticas más fundamentales y las más generales son producidas con la ayuda de alternativas, tratará de inventar tales alternativas. Desde luego, es imposible producir inmediatamente una teoría que sea formalmente comparable con el punto de vista principal y que conduzca al igual que este a muchas predicciones. Su primer paso por lo tanto será la formulación de suposiciones ampliamente generales que no están directamente conectadas con las observaciones; esto quiere decir que su primer paso será la invención de una nueva metafísica. Esta metafísica entonces debe ser elaborada con suficiente detalle en orden a ser capaz de competir con la teoría a ser investigada en cuanto a la generalidad, los detalles de predicción y precisión de formulación, Podemos resumir ambas actividades diciendo que un buen empirista debe ser un metafísico crítico. La eliminación de toda la metafísica, lejos de aumentar el contenido empírico de las teorías, es responsable de convertir a estas teorías en dogmas (Feyerabend, 1963/1999, p. 99).

Feyerabend desarrolla dos versiones o dos tipos de argumentaciones para defender la proliferación teórica. Una versión débil, según la cual las teorías alternativas indicarían cómo y qué pruebas o experimentaciones de la teoría imperante la ponen en cuestionamiento. Ante la ausencia de tales alternativas las teorías imperantes tienden a explicar esta evidencia recurriendo a hipótesis ad hoc (Cf. Feyerabend, 1960/1981b, pp. 223 y 226; 1993/2008, p. 27-28). Y una versión fuerte, según la cual las teorías alternativas son necesarias para descubrir experimentos cruciales capaces de refutar a una teoría vigente. Sin teorías alternativas dichos experimentos no estarían disponibles (Cf. Feyerabend, 1963/1999, p. 92; 1963/2013, p. 293; 1965, p. 175; 1970/1989, pp. 36 y ss.).

En un sentido fuerte defiende el pluralismo teórico en cuanto que éste permite obtener nueva evidencia que de otro modo sería imposible disponer, así como mostrar las dificultades y anomalías de las teorías imperantes. Argumenta que existen ciertos experimentos cruciales que sólo pueden obtenerse a través de la competencia de perspectivas teóricas (Cf. Feyerabend, 1962/1981b, pp. 71-72; 1965, pp. 216-

\footnotetext{
9 Preston (1997a, p. 78 y ss.) llama esto el 'predicamento del mito'.
} 
217; 1965/1981b, pp. 115 y ss). Escribe que "existen también hechos que no pueden ser descubiertos, excepto con la ayuda de teorías alternativas a la teoría a ser probada y que estos hechos dejan de estar disponibles tan pronto como son excluidas dichas alternativas" (Feyerabend, 1965, p. 175). Aún más, agrega que el carácter relevante y refutador de estos hechos decisivos solo puede ser establecido mediante teorías alternativas. Y expone nuevamente el rol que el pensamiento especulativo o la metafísica juega en su pluralismo metodológico:

La función de ideas metafísicas inusuales es definida de acuerdo a esto: ellas juegan un papel decisivo en la crítica y el desarrollo de lo que generalmente es creído y está "altamente confirmado ", ellas deben por lo tanto estar presentes en cualquier etapa del desarrollo de nuestro conocimiento. Una ciencia que está libre de la metafísica está en camino a convertirse en un sistema metafísico dogmático (Feyerabend, 1965, p. 150).

En respuesta a Laudan, quien le objeta haber convertido los problemas empíricos de la ciencia en problemas conceptuales y, por tanto, de no atender al contenido empírico de la ciencia Feyerabend (1981c) enumera episodios concretos de la historia de la ciencia en los que prueba que el descubrimiento de valioso material observacional ha sido rescatado justamente en virtud de los elementos conceptuales de otra teoría.

El caso de las predicciones del comportamiento estadístico del movimiento browniano parece ser un ejemplo paradigmático al que Feyerabend se refiere insistentemente para mostrar la necesidad y eficacia de su pluralismo teórico. Este caso ejemplifica la versión débil de su defensa de la proliferación teórica, a saber, en el demuestra que hubiera sido imposible descubrir de una manera directa la inconsistencia que existe entre el comportamiento de la partícula Browniana y la segunda ley de la termodinámica clásica. Pues, para ello, era necesario, en primer lugar, medir el movimiento exacto de la partícula en orden a determinar el cambio de energía cinética más la energía gastada en superar la resistencia del fluido; y, en segundo lugar, medir de un modo preciso la temperatura y el calor transferido al entorno en orden a determinar que cualquier pérdida ocurrida aquí esta compensada por el aumento de energía de la partícula en movimiento y el trabajo hecho contra el fluido. Tales mediciones estaban más allá de las posibilidades experimentales de la teoría termodinámica clásica. No era posible hacer mediciones precisas del calor transferido, ni trazar el camino transcurrido por la partícula con la precisión deseada. De aquí que una refutación 'directa' de la segunda ley considerando solamente la teoría fenomenológica y el 'hecho' del movimiento Browniano era imposible. Era necesario disponer - explica Feyerabend (1965, pp. 175-176; 1962/1989, p. 39)- de una nueva explicación alternativa del calor capaz de facilitar las técnicas de medición necesarias y así poner en evidencia los hechos que ponen en dificultad la teoría termodinámica clásica. 
En la segunda mitad del 1850 Rudolf Clausius, James Clerk Maxwell y Ludwig Boltzmann elaboraron la teoría cinética de los gases aplicando las leyes de la mecánica y del cálculo probabilístico al comportamiento de las moléculas individuales. Cincuenta años más tarde Einstein hizo uso de ella para calcular las propiedades estadísticas del movimiento de la partícula Browniana. Jean Perrin confirmó experimentalmente las predicciones de Einstein mostrando que las partículas son bombardeadas continuamente por el movimiento de las moléculas en el fluido. Perrin demostró que las moléculas de un gas son influidas por la fuerza de atracción de las otras moléculas. Este experimento constituyó un verdadero contraejemplo para la segunda ley de la termodinámica, según la cual, en un estado de equilibrio térmico el calor no puede transformarse completamente en trabajo; si no se realiza trabajo, es imposible transferir calor desde una región de temperatura más baja a una región de temperatura más alta.

Ahora bien, Feyerabend destaca que la experimentación de Perrin sólo fue posible una vez que fue desarrollada la teoría cinética de los gases. Con este caso paradigmático de la historia de la ciencia ilustra la fecundidad de su pluralismo teórico y demuestra que los resultados o la misma evidencia empírica de una teoría firmemente arraigada solo puede revelar un carácter refutador en la medida que se proponen y desarrollan nuevas teorías alternativas (Cf. Feyerabend 1961/1995, pp. 364-365; 1962/1989, p. 39; 1963/1999, pp. 92-93; 1964a, pp. 253-254; 1964c, pp. 351-353; 1965, pp. 175-176; 1975/1992, pp. 22-24;). Este es el argumento metodológico fundamental del vienés para defender o postular en un sentido fuerte la conveniencia de la proliferación teórica:

La función de tales alternativas concretas es, sin embargo, ésta: ellas proporcionan la posibilidad de criticar la teoría aceptada de una manera que va más allá de la crítica proporcionada por la comparación de aquella teoría "con los hechos". Aun cuando una teoría parezca reflejar los hechos, aun cuando sea usada universalmente, y aun cuando su existencia parezca ser la de aquellos que hablan el idioma correspondiente, su adecuación fáctica sólo puede ser afirmada una vez que ésta ha sido confrontada con alternativas cuya invención y desarrollo detallado debe preceder a cualquier aserción final acerca de su éxito práctico y la adecuación práctica. Esta es, desde luego, la justificación metodológica de una pluralidad de teorías: tal pluralidad permite una crítica mucho más aguda de las ideas aceptadas que la que puede proporcionar la comparación con un dominio de los hechos que se suponen dados independientemente de las consideraciones teóricas (Feyerabend, 1965, p. 150). Las cursivas son de original.

Una teoría alternativa -tal como la concibe Feyerabend- no sólo provee nuevas observaciones, o nuevos métodos o técnicas de medición, sino que incluso puede informar de significado y sentido a observaciones ya disponibles con anterioridad, tornándolas así capaces de cuestionar la validez de una teoría vigente. Daniel 
Sirtres y Eric Oberheim (2006) explican que las observaciones de las partículas Brownianas estaban disponibles mucho antes que Maxwell y Boltzmann en 1866 desarrollaran la teoría cinética. Sin embargo, -argumentan- sin las predicciones cuantitativas que hizo posteriormente Einstein, basándose justamente en la teoría cinética de los gases, estas observaciones simplemente carecerían de significado y no implicaban refutación alguna a la termodinámica clásica ${ }^{10}$.

10 Ronald Laymon (1977) argumenta contra Feyerabend que fue posible reconocer el movimiento Browniano como algo anómalo, como una contrainstancia de la Segunda ley de la termodinámica clásica, incluso sin la ayuda de una teoría alternativa. Laymon basa su tesis en los experimentos de variación concomitante de Gouy y en las afirmaciones de Poincare. Según Laymon, Gouy concluyó en 1968, sobre la base de los experimentos llevados a cabo, que la partícula B viola la segunda ley de la termodinámica; y la misma conclusión fue compartida por Poincare, antes que el artículo de Einstein haya sido publicado y los experimentos de Perrin hayan sido llevados a cabo. Fue el método de las variaciones concomitantes de Gouy en cuanto que muestra que los factores externos no son causantes de las fluctuaciones de temperatura en el fluido, y no una nueva teoría sobre el calor, lo que mostró las dificultades que presentaba el movimiento browniano a la segunda ley de la termodinámica -dice Laymon-. Luego la defensa de la proliferación teórica que consiste en mostrar que los hechos anómalos no están disponibles en la ausencia de teorías alternativas, no se sostiene. Ninguna teoría alternativa es o ha sido históricamente necesaria en orden a justificar las descripciones del movimiento Browniano que 'directamente' refutan la termodinámica clásica.

George Couvalis (1988) refuta a Laymon quien asegura que Poincare en 1904 concluyo que la segunda ley de la termodinámica ha sido definitivamente violada. Luego de citar el texto con el que Laymon pretende apoyar dicha afirmación, Couvalis destaca que en tal pasaje Poincare sostiene que los experimentos llevados a cabo mediante el uso de las variaciones concomitantes suministraron algunos motivos para sospechar de la segunda ley de la termodinámica. Estos motivos se limitaban a señalar lo siguiente: si el movimiento Browniano no toma prestado nada de las fuentes externas de energía, luego el principio el principio de Carnot (la segunda ley) es violada. Pero en ningún momento Poincare se compromete o da por resuelto que la ley ha sido efectivamente violada. Por el contrario, Couvalis destaca que cuando consideramos la situación de la física en el tiempo que Poincare escribió su artículo, advertimos su desgano por comprometerse con la visión de que la Segunda ley de la termodinámica ha sido refutada. En pocas palabras, Poincare en dicho artículo se limita a presentar la necesidad de llevar a cabo experimentos adicionales para determinar si el principio de Carnot ha sido violado o no. Además Couvalis asegura que las meras dificultades o anomalías- por ejemplo las que ponen de manifiesto las variaciones concomitantes de Gouy- no pueden invalidar un principio o teoría. Pues si aplicáramos este criterio ampliamente, hubiéramos rechazado automáticamente muchas hipótesis que al ser posteriormente comprobadas han significado importantes progresos científicos.

Por otro lado, los resultados de las variaciones concomitantes de Gouy no necesariamente implicaban la refutación de la segunda ley de la termodinámica. Estos resultados podrían haber sido objeto de una explicación coherente dentro de la misma termodinámica clásica. Couvalis explica que "el método de las variaciones concomitantes podría no haber sido utilizado por sí mismo para refutar la Segunda Ley porque la fuente del movimiento browniano podría haber sido resultado de la acción de una fuente de energía desconocida." (Couvalis, 1988, p. 418). La evidencia que aportan los resultados de las variaciones concomitantes solo podían tener un sentido y valor refutador en el marco de una nueva teoría. Luego la segunda ley de la termodinámica solamente podía ser refutada por las predicciones de una teoría rival, tal como la versión de la teoría cinética de Einstein.

Daniel Sirtres y Eric Oberheim (2006) despejan aún más la discusión al advertir que Gouy era un atomista ferviente; hecho que parece ser desconocido tanto para Laymon como para Couvalis. Gouy com- 
Feyerabend se concentra además en demostrar las ventajas de su pluralismo teórico frente al conservadurismo conceptual y al monismo teórico de Kuhn respecto al ideal positivista del aumento de contenido empírico.

Presenta su pluralismo teórico como el único camino por el cual es posible acceder a los ideales propios del positivismo lógico. Explica que sólo mediante la invención y consideración de teorías alternativas que contradicen al menos alguno de los principios del punto de vista aceptado es posible obtener nuevos hechos, y así aumentar el contenido empírico de la ciencia. Mientras que la proliferación teórica satisface esta exigencia del empirismo, un conservadurismo conceptual conduce a un estancamiento del progreso científico y a una consecuente crisis de los mismos ideales del positivismo (Cf. Feyerabend, 1969/1981, p. 157). Por ejemplo, muestra que el conservadurismo conceptual implícito en el principio de complementariedad de Niels Bohr es incompatible con la doctrina positivista adoptada por el físico. Pues al impedir descripciones alternativas a las que facilita la física clásica, dicho principio sería incapaz de explicar aspectos esenciales de los fenómenos cuánticos, $\mathrm{y}$, por tanto, de incrementar el contenido de la física, requisito esencial del empirismo (Feyerabend, 1958a).

Por otra parte, demuestra que el monismo teórico por el cual una única teoría es confrontada con la experiencia impide el aumento de contenido empírico y no describe correctamente el progreso científico. Argumenta que si el monismo teórico es prescripto normativamente - tal como según Feyerabend lo hace el empirismo lógico, Popper y la ciencia normal de Kuhn- se inhibe el desarrollo de la ciencia. Convierte las teorías científicas en auténticos mitos o dogmatismos pues la adhesión a una única teoría esclaviza al científico a explicar la realidad bajo un único punto de vista. La teoría incide de tal modo en el lenguaje, en el pensamiento y quizás aun en la percepción de la evidencia observacional que puede tornar incapaz al científico de imaginar una explicación alternativa de la realidad. En el monismo teórico no existe evidencia negativa, ni circunstancias en las que la teoría pueda resultar refutada. La teoría parece poseer una perfecta adecuación empírica. Pero este éxito empírico - explica Feyerabend (1963/1999, p. 95) ${ }^{11}$ - se logra a costa de disminuir el contenido empírico de la ciencia.

El monismo teórico, lejos de promover el progreso científico, convierte una única teoría en un sistema metafísico trascendental infalsable. La teoría, en nombre

partió las creencias del paradigma atomista y solamente porque lo hizo le fue posible llegar a la conclusión que el movimiento Browniano refuta la concepción clásica de la segunda ley de la termodinámica. Su confianza en las creencias atomistas le permitió excluir las otras posibles explicaciones de las que podían ser objeto los resultados de sus experimentos y reconocer en ellos el potencial refutador de la segunda ley que contenían. Luego, es imposible juzgar los méritos de las teorías sin contrastarlas con teorías alternativas.

11 Para acceder a un estudio crítico acerca de las ventajas de la proliferación teórica de Feyerabend frente al monismo teórico de Kuhn se puede ver: (Preston, 1997a, pp. 74-98 y 135 y ss.); (Munevar, 2006); (Farrell, 2003, pp. 190-192); (Hoyningen-Huene, 2000b, pp. 108-109). 
de la experiencia, deviene así en un dogma irrefutable. La coexistencia de teorías en competencia, en cambio, ofrece reinterpretaciones de las observaciones e incluso facilita la predicción de datos que ponen en dificultad a la teoría imperante -argumenta Feyerabend (1965, pp. 249-250, n. 122).

El vienés sostiene que incluso el progreso científico -tal como los concibe Thomas Kuhn- exige la proliferación teórica como proceso constituyente de los mismos periodos de ciencia normal. Kuhn asegura que la ciencia avanza a través de las revoluciones científicas las cuales no son producidas por las anomalías sino por la presencia de paradigmas alternativos que prometen explicar tales alternativas. Luego es lógico que nuestro filósofo le proponga crear más crisis y por ello más cambio fructífero en los propios términos de Kuhn, es decir, mediante la continua invención de nuevas teorías alternativas. Si Kuhn está dispuesto a admitir que las revoluciones científicas sólo son posibles en cuanto se compara el paradigma imperante con teorías alternativas, debe reconocer también que la proliferación no sólo es simultánea a la revolución científica sino que es un instrumento esencial que la precede y la facilita:

Kuhn no sólo ha admitido que la multiplicidad de teorías cambia el estilo de argumentación. También ha atribuido una función definitiva a tal multiplicidad. Ha señalado más de una vez... que las refutaciones son imposibles sin la ayuda de alternativas. Además, ha descrito con algún detalle los magníficos efectos que las alternativas tienen sobre las anomalías y ha explicado como las revoluciones son ocasionadas por tal amplificación. Por lo tanto ha dicho, en efecto, que los científicos crean revoluciones conforme a nuestro pequeño modelo metodológico y no por sostener despiadadamente un paradigma y de repente abandonarlo cuando los problemas se hacen demasiado grandes (Feyerabend, 1970/1981c, p. 140).

La pluralidad de teorías no debe ser considerada como un estado preliminar del conocimiento científico. La ciencia no es la sucesión de periodos normales y períodos de proliferación; sino la yuxtaposición de ambos momentos. En la ciencia madura, preexisten dos tradiciones: una que se caracteriza por el ejercicio crítico de un pluralismo filosófico y otra más práctica que explora las potencialidades de una teoría o paradigma en particular. Feyerabend demuestra a Kuhn que la proliferación teórica junto con el análisis crítico de las teorías es esencial para superar el dogmatismo y para estimular el progreso científico y, por tanto, no puede ser excluido como pre-científico o restringido a los períodos de crisis o revoluciones científicas. En otras palabras, el vienés (1962/1981a, p. 325; 1965/1981b, p. 108, n. 14; 1970/1981c, p. 135, 144-147) argumenta contra Kuhn que el periodo pre-científico caracterizado por la proliferación es esencial a los periodos científicos ${ }^{12}$.

12 Preston (1997a, pp. 92-93) observa que Kuhn en 1961 admite que la ciencia madura no es una empresa enteramente monolítica. No obstante, Kuhn sigue enfatizando el carácter cuasi-independien- 
Feyerabend, como se expuso más arriba, no defiende positivamente la concepción popperiana acerca del aumento de contenido. Lo que le interesa exponer al vienés por medio de una reducción al absurdo es que esta noción de progreso científico exige paradojalmente la adopción de la proliferación teórica y en consecuencia la revalorización de la especulación metafísica como el método por excelencia que posibilita el progreso científico.

El ideal de aumento de contenido reivindica la importancia no sólo psicológica sino, sobre todo, metodológica de la metafísica. Feyerabend no se limita a exponer -en línea con la tradición popperiana-el valor psicológico o imaginativo de la especulación metafísica para la invención de nuevas teorías. Defiende su valor metodológico mostrando que sin las teorías ontológicamente incompatibles es imposible aumentar el contenido empírico de la ciencia y disponer de instancias refutadoras que permitan superar los dogmatismos en los que devienen las teorías imperantes.

\section{El ideal de la Proliferación Teórica como Cumplimiento de su Realismo Normativo}

Feyerabend no se limita a defender a la metafísica como un mero dispositivo psicológico que interviene en la invención de nuevos modelos explicativos. En el apartado anterior se presentó la conveniencia metodológica de la metafísica, o de teorías ontológicamente inconmensurables para dar cumplimiento al ideal popperiano y positivista de aumentar el contenido empírico de la ciencia. En este punto se exponen las argumentaciones por las cuales el vienés busca dar cuenta del rol que juegan en el proceso de explicación teórica todos aquellos elementos que el positivista lógico o el mismo Popper reconocen como metafísicos. Las visiones metafísicas constituyen para Feyerabend la base del intento por explicar científicamente el mundo. En una carta que Feyerabend (1961/1995, pp. 368-369) escribe a Kuhn alrededor del año 1961 explica que se deben cultivar en las ciencias las teorías alternativas en orden a poder continuar con la investigación realista de las propiedades del mundo.

En virtud de la metafísica, las leyes pueden ofrecer una explicación racional de los fenómenos naturales, contribuir al desarrollo o extensión de los contextos teóricos existentes y promover explicaciones comprehensivas donde ningún fenómeno deje de ser explicado. Las generalizaciones empíricas, en cambio, se limitan a condensar y predecir hechos observacionales sin disponer de una explicación o razón para tales correlaciones. En la recensión que escribe para un libro de Harré, luego

te de cada paradigma por lo cual cada uno de ellos se aboca a resolver sus propios problemas. Contra esta última posición Feyerabend replica nuevamente que las crisis o revoluciones científicas dependen no de la aparición de anomalías sino de la interacción activa entre los paradigmas inconsistentes de la ciencia madura. 
de exponer la preocupación del éste por determinar qué es una explicación científica satisfactoria, el vienés apunta que el autor tiene que preguntarse en definitiva por el rol que juega la metafísica en el proceso de explicación teórica. Harre debería reconocer -según Feyerabend (1961b, p. 245-246)- el rol fundamental que juega la metafísica en las argumentaciones que constituyen estas explicaciones científicas satisfactorias.

Feyerabend está convencido que sin la metafísica la ciencia no puede dar cuenta del mundo. De aquí que en su Tratado contra el Método escriba que la ciencia al abandonar sus pretensiones cognoscitivas, "ha dejado de ser una aventura filosófica para convertirse en una profesión" (Feyerabend, 1975/1992, p. 185).

En la bibliografía especializada en la obra del vienés existe una discusión acerca de si éste defiende un realismo científico o un anti-realismo (Cf. Preston, 1997a, pp. 61-73; Oberheim, 2006, pp. 180-205; Llyod 1996, p. 252; Boyd 1992). Estas controversias exigen esclarecer esta cuestión en orden a poder comprender en qué sentido Feyerabend sostiene que la metafísica provee vías de acceso para explicar el mundo.

Feyerabend ataca la visión instrumentalista de la ciencia ${ }^{13}$ (Cf. Feyerabend, 1958/1981a; 1958a; 1958c; 1960/1981a; 1961/1999; 1964/1981; 1975/1992; $1981 b ; 1993 / 2008)$ y el realismo científico desde el realismo normativo que asume. Para él, el realismo científico es injustificable como descripción de las teorías científicas actuales pero es aceptable si se lo considera como un ideal que contribuye al progreso científico.

El realismo científico es definido a través de una vasta literatura ${ }^{14}$ por dos tesis. Una de carácter epistémico que postula la posibilidad de acceder cognoscitivamente al mundo y otra de carácter metafísico que dicta la existencia de un mundo externo e independiente del sujeto cognoscente. Esta noción de realismo científico es la que Preston (1997b, p. 61 y 421) no duda en adjudicar a Feyerabend 15 tomando como apoyo textos en los que el vienés asume efectivamente dichas tesis. (Cf. Feyerabend 1958a, pp. 75-104; 1958/1981a, pp. 17-36; 1958/1981b, pp. 236-246; 1960a, pp. 321-338). Pero lo que Preston no parece advertir es que en dichos pasajes Feyerabend asume dichas tesis del realismo científico pero en orden a reducirlas al absurdo.

\footnotetext{
13 Para acceder a estudios críticos sobre a la posición de Feyerabend respecto a la disputa realismoinstrumentalismo (Cf. Preston, 1997a, pp. 61-73; 2009, pp. 11-12; Farrell, 2003, pp. 121-122; 2000, pp. 258-263; Moore, 1972; Laymon, 1977, pp. 232-233; Hoyningen-Huene, 2000a, pp. 10-11; Oberheim, Hoyningen-Huene, 2000, p. 366).

14 Oberheim (2006, p. 196, n. 273) ofrece una extensa lista de autores que discute actualmente a favor o en contra del realismo científico.

15 Aunque Feyerabend defienda el realismo entre 1950 y 1960, en ningún pasaje aboga a favor de un realismo científico como sugiere erróneamente Preston. Para una refutación a Preston se puede ver: (Oberheim, Hoyningen-Huene, 1999, p. 229 y ss.; Oberheim, 2006, pp. 180-205).
} 
En su teoría pragmática de la observación nuestro epistemólogo reconoce una realidad externa como fuente de las percepciones del observador. Pero en ningún momento reconoce que esta realidad externa e independiente del sujeto cognoscente pueda ser conocida en cuanto tal, o que el conocimiento científico descubre la verdad o la estructura objetiva del mundo ${ }^{16}$. Por el contrario insiste que el progreso científico no puede ser concebido como la convergencia de múltiples teorías hacia un único punto de vista o hacia el descubrimiento gradual de la verdad:

El conocimiento así concebido no es un proceso que converge hacia una visión ideal; se trata de un océano siempre creciente de alternativas, cada una de las cuales fuerza a las demás a una articulación cada vez mayor, todas ellas contribuyen, a través de este proceso de competición, al desarrollo de nuestras facultades mentales (Feyerabend, 1965/1981b, p. 107).

Explícitamente Feyerabend niega haber querido esbozar una especie de neorealismo, o de postular que las teorías acceden cognoscitivamente a una realidad objetiva. Pues esto, según él, atentaría contra la unidad entre ciencia y filosofía que procura postular:

Quizás involuntariamente él [Smart] crea la impresión de que he contribuido al desarrollo de una nueva posición filosófica, que he fabricado una especie de neorrealismo. Tal impresión sería tanto incorrecta, como desafortunada... Esto aumentaría la tendencia a desatender la conexión entre la filosofía y las ciencias que son tan esenciales para el desarrollo de nuestro problema (Feyerabend, 1965, p. 249).

Estos textos nos permiten inferir que Feyerabend no puede ser inscripto dentro del realismo científico sino más bien -al menos entre los años 50 y 60- dentro de una metafísica no-realista. De hecho la tesis de la existencia de un mundo es compatible con múltiples formas de anti-realismo17 tales como la metafísica neo-kantiana de Kuhn (Cf. Hoyningen-Huene, 1993; Sankey, 1994; 1997a; 1997b; 1998; Caneva, 2000; Bird 2002), el realismo interno de Putnam (1981) y el empirismo constructivo de Van Fraassen (1984). No así el realismo científico el cual se caracteriza justamente por plantear distintas posibilidades de acceder epistemológicamente a la realidad externa.

16 Feyerabend no postula una versión fuerte de realismo según la cual una teoría es verdadera si las entidades postuladas por ella efectivamente existen y existirían independientemente de toda formulación teórica. Para él las entidades teóricas o sensoriales no poseen una existencia real e independiente de las mismas teorías que las postulan y explican. Lo que propiamente existe es el marco teórico que proyecta los datos sensoriales (Cf. Feyerabend, 1960/2005, pp. 299-300; 1989, pp. 393-400).

17 Oberheim (2006, p. 185, n. 257) sostiene que es más apropiado adjudicarle a Feyerabend una posición 'no-realista' que un 'anti-realismo' pues la visión del vienés no es diametralmente opuesta al realismo. Difiere del realismo en solo una de sus tesis, a saber, en aquella que versa sobre la posibilidad de acceder cognoscitivamente a lo real. 
El filósofo vienés argumenta que las teorías científicas deben ser concebidas como intentos de describir realísticamente la experiencia y no como meros instrumentos que sistematizan la experiencia; de aquí que uno de sus artículo se titule $A n$ Attempt at a Realistic Interpretation of Experience (1958b) ${ }^{18}$. Asume el realismo como un ideal metodológico normativo que presenta ciertas ventajas y conveniencias en orden a alcanzar los objetivos de la ciencia. Primero, porque en una interpretación realista de las teorías científicas se supone que la naturaleza no posee sino una única naturaleza por lo cual sólo una de las teorías puede ser correcta. En una concepción realista las teorías se ven obligadas a competir y de este modo en ella se incrementa la severidad de los experimentos cruciales. En una interpretación instrumentalista, en cambio, pueden coexistir dos teorías mutuamente contradictorias puesto que ellas no intentan describir la naturaleza de lo real. Segundo, Feyerabend (1958/1981a, p. 17; 1958a, p. 101 y ss.; 1958/1981b, p. 237 y ss.; 1962/1981b, p. 83; 1963/1981, pp. 161-175; 1965/1981a, pp. 97-103) aboga por un realismo normativo porque una interpretación realista de la experiencia promueve el desarrollo de nuevos puntos de vista. Ante la relación de inconsistencia que puede existir entre teorías, un realista se ve obligado a mejorarlas o sustituirlas por otras nuevas teorías.

Nuestro epistemólogo asegura que la elección entre realismo e instrumentalismo depende de algo más que de una mera predilección lingüística tal como parece sostener Nagel. Explica que tal elección depende, en definitiva, de una cuestión metodológica, a saber, si no se desarrollan teorías en el sentido fuerte, es decir, como descripciones alternativas de la realidad, es imposible descubrir las dificultades que albergan las teorías imperantes:

En este ensayo afirmo que el realismo es preferible al instrumentalismo [...] Esto es porque la invención de nuevas teorías que son inconsistentes con el punto de vista aceptado viene exigido por el principio de contrastabilidad, y esto es también la prometida justificación metodológica para el realismo (Feyerabend, 1964/1981, p. 176).

El realismo normativo promueve mucho mejor el progreso que el instrumentalismo. Pero el epistemólogo no postula su realismo como una descripción de la naturaleza del conocimiento y del progreso científico. Feyerabend es claro a este respecto. Escribe que "La cuestión entre el positivismo y el realismo no es una cuestión de hecho que pueda decidirse señalando ciertas cosas realmente existentes, procedimientos, formas de lenguaje, etc., ésta es una cuestión de ideales de conocimiento" (1958/1981a, pp. 33-34). Feyerabend no ofrece pruebas de inducción sino sólo consideraciones metodológicas para postular -a modo de conjetura- la exis-

\footnotetext{
18 Feyerabend (1960/1981b, p. 224) reconoce tanto a Popper como a Kraft como las fuentes de su realismo normativo. Oberheim (2006, p. 191) precisa aún más la incidencia de estos filósofos, indicando que Feyerabend adapta el realismo normativo de Kraft al realismo conjetural de Popper.
} 
tencia de un mundo externo ${ }^{19}$. Pero él mismo asegura que inicialmente una conjetura no es más que una hipótesis injustificada (Cf. Feyerabend, 1963, pp. 321$322)^{20}$.

La proliferación teórica satisface las exigencias de este realismo normativo. Pues ya sea que exista o no una estructura inherente al universo, la proliferación presenta sus ventajas. Si existe, la proliferación ayudará a descubrirla; pero si no existe tal estructura la proliferación significará un auxilio para desterrar aquellos sistemas de pensamiento auto-consistentes (Cf. Feyerabend, 1975/1992, p. 4).

En comunión con la tradición neo-kantiana Feyerabend postula el carácter teórico e histórico de la naturaleza. Subraya que las concepciones del mundo o categorías varían históricamente organizándose por ello la experiencia de diversas maneras. Rechaza el carácter necesario e inalterable que Kant adjudica a las categorías o formas puras del entendimiento:

Podemos decir incluso que lo que se considera "naturaleza" en una época determinada es un producto nuestro, en el sentido de que todos los rasgos que se le adscriben han sido primero inventados por nosotros y usados después para otorgar orden a lo que nos rodea. Como es bien sabido, fue Kant quien investigó con más insistencia este carácter omnicomprensivo de los supuestos teóricos. Sin embargo, Kant también creía que la misma generalidad de tales supuestos y su omnipresencia impiden que puedan ser refutados (Feyerabend, 1962/1989, p. 40).

El vienés se aleja de los trascendentales de Kant pues niega el carácter universal, necesario o invariante, que éste concede a los mismos. Toda teoría supone ciertos presupuestos ontológicos que definen una particular concepción de la realidad. Pero tales principios - explica- no son verdades apodícticas; no constituyen tesis necesarias, incondicionadas y demostrables. Proporcionan únicamente un esbozo conceptual, siempre hipotético y provisorio, del mundo por lo cual siempre está abierto a la posibilidad de ser criticado y reformado (Cf. Feyerabend, 1958a, pp. 8184; 1958/1981a, pp. 22-23; 1962/1989, p. 40; (1960/2005), p. 294).

Los principios ontológicos tal como los entiende Feyerabend difieren, además, de los trascendentales de Kant en cuanto que estos últimos son apriorísticos. Para el vienés los principios ontológicos no son una mera generalización de la experiencia pero tampoco son principios a priori conocidos independientemente de la expe-

${ }_{19}$ La creencia o adhesión a una cosmovisión no se funda en una inducción, ni en algún tipo de pruebas, ni en la relación de adecuación que aquella pueda guardar con los hechos. Pues todo ello para Feyerabend es posterior a la elección o adhesión a una determinada ontología. Cf. Feyerabend (1958/1981a), 24; (1962/1989), 56 y 74; 1963, 323; 1991/2003, 70).

20 Feyerabend, en continuidad con la tradición popperiana, entiende los principios ontológicos o metafísicos como el conjunto de creencias o conjeturas injustificadas acerca de la naturaleza de la real que carecen inicialmente de todo fundamento (Cf. Popper, 1962, p. 38). 
riencia. Se arriba a ellos por medio de la reflexión filosófica acerca de la naturaleza tal como ésta se nos presenta en el sentido más amplio. Los principios ontológicos no son asumidos con independencia de cualquier experiencia en absoluto, pero sí son asumidos independientemente de cualquier experiencia científica, dado que cualquier experiencia científica posterior los presupone. Una vez que son formulados estos principios constituyen las precondiciones a partir de las cuales una teoría experimenta el mundo. De aquí que nuestro epistemólogo (1970/1989, pp. 91-92) los reconoce como relativamente a priori.

La ontología que informa las teorías científicas constituye los fenómenos que experimentamos y ofrece la clave interpretativa para explicarlos. El conocimiento del mundo no es dado directamente -insiste Feyerabend (1963/1999, p. 91 y ss.; 1962/1981b, p. 46; 1965, p. 216)-. Sólo se accede a él a través de la competencia de visiones del mundo mutuamente inconmensurables. Esta proliferación de metafísicas u ontologías representa para él la única vía posible de concretar la referencia o el contenido ontológico de la actividad científica; y, de este modo, dar cumplimiento -según su realismo normativo- al ideal cognoscitivo de la ciencia.

Feyerabend da cuenta de la necesidad de la proliferación de ontologías en sus estudios críticos en torno al principio de complementariedad de Bohr. En ellos presenta el auxilio que pueden prestar las visiones ontológicas recíprocamente inconmensurables en orden a que la teoría cuántica se constituya en un intento por describir realísticamente los comportamientos cuánticos.

Por ejemplo, señala (Cf. Feyerabend 1962/1981a) la paradoja que implica el carácter instrumental de la teoría cuántica. Explica que quizás ninguna otra teoría en la historia de la física haya dispuesto a su favor de un caudal tan inmenso de formalismos matemáticos, material observacional y experimentaciones, como lo ha hecho la teoría cuántica. No obstante, apunta que en ésta permanece confusa la verdadera entidad y naturaleza de su objeto21. La teoría cuántica constituye un sistema axiomático con éxito predictivo capaz de establecer cierto orden en la constante acumulación de material empírico. Pero no ofrece una comprensión teórica de los fenómenos cuánticos y en cuanto tal no constituye propiamente para Feyerabend $(1968 / 1981 ; 1960 / 1981$ a) una teoría o un intento por explicar realísticamente a los fenómenos cuánticos. Las imágenes antagónicas de 'onda' y 'partícula' pierden, por ejemplo, en el principio de complementariedad de Bohr algunas de sus propie-

\footnotetext{
21 El método usado, por ejemplo, para la determinación de un estado estacionario es de una naturaleza formal; nos da números -explica Feyerabend- pero no nos permite decir qué proceso particular objetivo es responsable de la aparición de estos números. Se puede determinar en qué medida los fenómenos cuánticos no son una onda y en qué medida no son un corpúsculo pero no es posible determinar su referencia ontológica. Por ende el científico, está obligado a mantener siempre en mente la aplicación restringida de la física cuántica y a abstenerse en ella de toda "inferencia ontológica", o de toda "pretensión realista" (Cf. Feyerabend, 1958a, p. 92; 1960/1981a, pp. 220-221; 1968/1981, p. 278.
} 
dades intuitivas esenciales como son su velocidad bien determinada o su exacta localización en el espacio. Carecen en definitiva de un contenido descriptivo, de una significación física para convertirse en meros símbolos o herramientas que permiten predecir el comportamiento de los micro-objetos.

Niels Bohr -sostiene Feyerabend cuando mejora su comprensión del físicoconcibe su principio de complementariedad como un esquema predictivo 22 . Pero no por ello el físico abandona o rechaza el ideal de una explicación realista, es decir, la posibilidad de que la teoría cuántica sea subsumida en una teoría general cuyos conceptos sean universalmente aplicables. Bohr está convencido que esta formalización matemática debería estar precedida por una completa explicación física y teme justamente que la formalización matemática oscurezca el núcleo de los problemas físicos de la teoría cuántica -explica Feyerabend (1958a) ${ }^{23}$.

Este escepticismo respecto al contenido ontológico de su principio de complementariedad, revela a Feyerabend la preocupación metafísica del físico. La conciencia de Bohr acerca de las limitaciones de su propio modelo atómico manifiesta la naturaleza metafísica de su perspectiva. Según el vienés (1968/1981) la crítica de Bohr es epistemológica, no física en el sentido tradicional de la palabra. Bohr supera la actitud propia del físico matemático que se limita a lo formalmente satisfactorio y a las ecuaciones fácticamente adecuadas. Para él todas las teorías científicas, junto con sus problemas técnicos, están siempre relacionadas con perspectivas filosóficas. Para Bohr sin ellas no solo no se podrían resolver los problemas sino que tampoco se podría comprender lo que las teorías científicas significan o hacia donde nos conducen.

En resumen, Bohr reconoce que su principio de complementariedad no ofrece sino un puro sistema axiomático que nos permite predecir el comportamiento de los

\footnotetext{
22 Feyerabend (1962/1981a) explica que la teoría cuántica fue creada por Schrödinger quien la interpretaba desde una óptica realista. O sea que históricamente esta teoría nació en el marco de una metafísica diametralmente opuesta a la perspectiva de Niels Bohr y de sus discípulos. Por otra parte afirma que la escuela de Copenhague, nunca produjo una teoría, simplemente interpretó la mecánica de Schrödinger desde una perspectiva positivista. En oposición a Shrödinger, Bohr sostiene que las leyes de la física cuántica no pueden ser consideradas como reglas o nociones que describen las características universales de un mundo diferente al de la física clásica.

23 Don Howard (2004) sostiene que Bohr no deja de conceder un sustrato real a los fenómenos cuánticos, aunque destaca que no puede describirlos como una 'realidad independiente'. El objeto observado y el aparato de medición constituyen para Bohr -explica Howard- un par indisoluble tal que no pueden ser distinguidos como realidades separadas. Luego Bohr no sostiene el anti-realismo que a menudo se le atribuye Evidentemente Howard, acierta al destacar la inevitable interacción y unidad entre los objetos y los instrumentos de medición señalada por Bohr. No obstante no atiende a la oposición del físico a otorgar un contenido real a los resultados de estas agencias de observación. Éstas nos permiten, según Bohr, predecir el comportamiento de los fenómenos pero nada nos dicen acerca de la naturaleza de sus resultados. De aquí la dificultad que existe para adjudicar un realismo efectivo al principio de complementariedad.
} 
fenómenos cuánticos. Por ende, es consciente según Feyerabend de la necesidad de elaborar teorías que precedan absolutamente la formulación matemática y que sean capaces de facilitarnos un entendimiento más profundo de la naturaleza de los micro-procesos.

No obstante Bohr exige que estos nuevos modelos de explicación sean formulados en los términos propios de la física clásica. Contra esta restricción el vienés (1958a) postula la proliferación de teorías ontológicamente inconmensurables como la única vía por el cual la física cuántica podría adquirir un verdadero fundamento teórico. La metafísica se le presenta como la única fuente de nuevas teorías o descripciones hipotéticas acerca de la estructura y naturaleza del mundo físico. Y, por tanto, sólo ella es capaz de conceder a la estructura formal de la teoría cuántica una interpretación que le confiera una referencia ontológica. De la metafísica se podría obtener un esquema conceptual distinto al que nos sugiere la sola lectura y consideración de la experiencia facilitada por la física clásica.

Feyerabend presenta y defiende su pluralismo teórico como un procedimiento realista que alienta el progreso científico a través de todas las direcciones racionales posibles:

Solamente la invención de un nuevo conjunto de ideas que audazmente se opongan a las apariencias y creencias comunes y que intenten explicar a ambas de un modo profundo, podría luego conducirnos a un progreso adicional y permitir una argumentación racional. Esto muestra la conexión cercana que existe entre lo que ha sido llamado el ideal clásico o realismo por un lado, y el progreso científico por el otro (Feyerabend, 1958a, pp. 103-104).

Por otro lado, la eliminación de la misma doctrina inductivista y el regreso al modo clásico de explicación permitiría nuevos progresos en la ciencia y, en este caso, facilitaría una interpretación ontológica de la teoría cuántica. Por modelo clásico de explicación, Feyerabend entiende un ideal de conocimiento estrechamente conectado al realismo normativo. Éste exige dos condiciones. En primer lugar, la teoría debe ser empíricamente adecuada; en este caso, debe explicar completa y exhaustivamente todos los comportamientos cuánticos que se obtienen a través de la imagen corpuscular y la ondulatoria. En segundo lugar, la teoría debe ser universal, es decir, debe ser de tal forma que nos permita decir qué es la luz y no describir simplemente cómo la luz aparece bajo diversas condiciones.

En este punto la postura de Feyerabend (1960/1981a; 1961/1995) encuentra una mayor afinidad con Bohm quien sugiere elaborar un aparato conceptual completamente nuevo el cual ya no haría uso de las ideas clásicas. Este esquema originariamente sería 'extrafísico' en el sentido que no sería susceptible de ser comprobado por los métodos disponibles hasta ese momento. La misma historia de la investigación científica, según Bohm, está llena de ejemplos que muestran lo fructífero que 
es asumir que ciertos objetos y elementos podrían ser reales, mucho antes que cualquier procedimiento conocido pueda observarlos directamente 24 .

Nuestro filósofo de las ciencias advierte y señala las dificultades e inconsistencias que crecen alrededor del intento de acceder a una interpretación realista de la mecánica cuántica. Expone, por ejemplo, las inconsistencias que se derivan de Broglie y Schrödinger quienes rechazaron la hipótesis de los estados indefinidos de descripción señalando que esta simplemente es consecuencia del carácter incompleto de la teoría cuántica postulada por Bohr, sobre todo del carácter estadístico de su teoría. En su lugar, intentaron desarrollar una teoría completamente nueva en orden a describir la naturaleza y el comportamiento de los sistemas cuánticos proponiendo que las entidades microfísicas tienen un estado bien definido. Feyerabend (1964/1981) muestra que tal interpretación realista, aparte de no tener ningún hecho experimental que la sostuviera, en aquel entonces, era inconsistente con observaciones y leyes físicas bien confirmadas.

El vienés advierte que no se trata simplemente de estar a favor de una interpretación realista de la mecánica cuántica. El instrumentalismo o el realismo de la teoría cuántica no es una posición filosófica que pueda ser discutida únicamente mediante argumentos generales. El epistemólogo nos previene de la ingenuidad de llevar a cabo el siguiente razonamiento: el instrumentalismo de la teoría cuántica es un resultado del positivismo; el positivismo es falso; luego debemos interpretar la teoría cuántica de un modo realista. El razonamiento es confuso. Pues por interpretar las ecuaciones matemáticas o los resultados estadísticos de un modo realista no por ello éstos adquieren ipso facto una implicancia ontológica. Tal interpretación solo sería un prejuicio filosófico, un dogmatismo. El razonamiento, además, no sólo sería confuso - explica Feyerabend- sino también irrelevante para el problema de la interpretación de la física cuántica. Estos argumentos epistemológicos no refutan, ni tocan en absoluto los argumentos desarrollados por los físicos. Únicamente contribuyen a "una muy indeseable escisión entre la física y la filosofía" (Feyerabend, 1964/1981, p. 185). Mientras los físicos apelan a su favor innumerables y fructíferos experimentos; los filósofos realistas desarrollan argumentos abstractos que en absoluto refutan el mérito de aquellos. Ni los unos ni los otros invalidan el punto de vista del adversario. Estos sostienen dos cosmovisiones inconmensurables sin ningún puente de diálogo o comunicación. Luego, es imperativo, según el vienés, evitar los círculos viciosos de este tipo y atacar el instrumentalismo donde este parece ser más fuerte, es decir, refutar los resultados fácticos específicos que lo confirman.

Para Feyerabend es necesario desarrollar una teoría con tal detalle que pueda ofrecer una explicación alternativa de todos los experimentos cuánticos que se han

\footnotetext{
24 También el método de Einstein -según Feyerabend (1966)- está mucho más preparado que la interpretación de Copenhague para inventar visiones extremas y hacer de hechos aislados el punto de partida de una nueva visión del mundo.
} 
desarrollado hasta el momento o muestre que los resultados experimentales que se han obtenido no son estrictamente válidos. No sólo es necesario elaborar una nueva teoría de los fenómenos cuánticos con implicancias ontológicas, sino también demostrar que la misma es experimentalmente tan valiosa como la teoría que ha sido usada hasta el presente. Feyerabend (1981a), en este sentido, señala como un físico paradigmático a Einstein quien inició no sólo interesantes desarrollos teóricos sino que también supo proporcionar experimentos que clarificaban conceptos básicos de la teoría cuántica. Elaboro experimentos cruciales que reforzaban una interpretación realista de la física cuántica y refutaban el núcleo de la visión instrumentalista. Esta es una formidable tarea, que según el vienés no ha sido aún reconocía por los campeones puramente filosóficos del realismo en microfísica.

Por otro lado, el programa de interpretación de la propensión de Popper es presentado por Feyerabend (1968/1981) como un claro ejemplo de las ingenuas pretensiones realistas. Ante la constatación de que la física cuántica no ofrece un cuadro de la realidad sino un mero aparato de predicción de los micro-objetos; al quedar rechazado el programa de Faraday-Einstein-Schrödinger, Popper elabora una interpretación realista de la probabilidad que intenta solventar la falta de un interpretación física de la teoría cuántica con la proposición de otro programa, al que designa 'programa metafísico de la interpretación de la propensión'. Lo concibe como un 'programa de investigación' en cuanto que incorpora una idea general de lo que habría de ser una solución satisfactoria de los problemas. Y 'metafísico' en cuanto que ofrece una visión general de la estructura del mundo y de la situación de la cosmología física. Popper escribe:

El indeterminismo y la interpretación de la probabilidad como propensión nos han de permitir un nuevo cuadro del mundo físico. De acuerdo con dicho cuadro, del cual solo los trazos más gruesos pueden darse aquí, todas las propiedades del mundo físico en cualquier momento pueden ser concebidas como una suma de sus disposiciones (o de sus potencialidades, posibilidades o propensiones) (Popper, 1982, pp. 159-160)25.

\footnotetext{
25 Popper formula una imagen del mundo, todas las propiedades físicas del mundo no son más que propensiones, posibilidades o potencialidades. El cambio no es más que la actualización o realización de estas potencialidades. Una vez que se han actualizados estas potencialidades se crea una nueva situación que da lugar a un nuevo conjunto de potencialidades. Obtenemos así un cuadro del mundo que es a la vez dualístico y monístico. Es dualístico en tanto que las potencialidades son potencialidades sólo relativas a sus posibles realizaciones o actualizaciones; y es monístico en tanto que las realizaciones o actualizaciones no sólo determinan las potencialidades, sino que debe decirse que son potencialidades ellas mismas. De este modo, Popper describe el comportamiento de los cuantos como propensiones para el cambio aclarando que aunque estas propensiones no determinan en general los cambios futuros, pueden determinar, al menos, las distribuciones de probabilidad.

Feyerabend (1968/1981) hace notar en una nota que introduce en 1980 en el artículo Niels Bohr's world view, que la teoría de la propensión fue introducida por Bohr mucho antes que Popper empezara a pensar en ella. Aún más afirma que es mucho más rico el principio de complementariedad que la
} 
Feyerabend destaca la contradicción de Popper al reconocer el carácter formal de la teoría cuántica y proponer simultáneamente una interpretación metafísica de la propensión. El que fue su director de estudios parece dar por sentada, sin ningún debate adicional, la posibilidad de hacer inferencias ontológicas a partir de los resultados estadísticos en los que se expresan los comportamientos cuánticos. Popper establece que la teoría cuántica es esencialmente estadística o probabilística. Y a partir de allí elabora su programa de interpretación. Pero Feyerabend (1968/1981) señala que éste es precisamente uno de los puntos en discusión, a saber, si la teoría cuántica es puramente estadística o si las probabilidades que arrojan las estadísticas obedecen a leyes en sí mismas no-estadísticas. Popper parece no contemplar esta segunda alternativa.

Ante los experimentos subatómicos existen para Feyerabend al menos dos alternativas: $\mathrm{O}$ los fenómenos o comportamientos cuánticos poseen valores bien definidos independientemente de las condiciones experimentales en las que se inscriben; o estos valores reflejan un estado que es resultado de la interacción entre distintos factores o condicionamientos. Pues bien, a pesar del gran éxito empírico de la interpretación estadística, ésta no nos provee de ningún elemento -afirma el vienés (1968/1981) - para decidir entre la primera y segunda alternativa. Las estadísticas de muertes no nos permiten esbozar ninguna conclusión respecto al modo en que han tenido lugar dichas muertes, ni nos permiten inferir si los seres humanos son o no entidades cuyos rasgos son independientes de la observación. No obstante, Popper en un acto de 'ingenuidad infantil' -escribe Feyerabend (1968/1981)- establece de modo a priori, sin justificación alguna, que una partícula elemental posee un valor bien definido en oposición a todas las pruebas existentes a favor del carácter relacional de las magnitudes dinámicas, pues los elementos que son objeto de las predicciones estadísticas deben tener prácticamente todas las propiedades de una partícula clásica. Para Popper las propiedades dinámicas deben ser definidas con una precisión mucho mayor a las incertidumbres de Heisenberg. Ahora, esto sólo es posible si suponemos que las mediciones no introducen nuevas condiciones. Popper también da por resuelta o verdadera tal suposición.

El blanco de la crítica de nuestro filósofo estriba en mostrar que, aun dando por supuesto que se trata de una teoría estadística, podemos inferir que esta funciona pero no podemos esbozar ninguna inferencia acerca de las propiedades individuales de los fenómenos, eventos o proceso cuánticos. Lo único que nos ofrece una teoría estadística son los valores esperados de estos elementos bajo ciertas condiciones bien definidas. Hasta que esta nueva teoría cuántica pueda ser construida acabada-

teoría de la propensión de Popper pues ésta última simplemente dice que las probabilidades cambian una vez que cambian las condiciones. La complementariedad, en cambio, permite ver cómo las propensiones pueden ser incorporadas dentro de la teoría cuántica, y nos informa acerca de qué propiedades están relacionadas con determinadas disposiciones experimentales y cómo estas cambian en la presencia de fuerzas o de otros procesos compatibles con la condiciones de su aplicación. 
mente debe adoptarse -según Feyerabend (1964/1981) - una interpretación instrumentalista, es decir, se debe reconocer que sólo se dispone de un esquema predictivo de los fenómenos cuánticos. Pues hasta los años 60 , la única explicación que se disponía de los comportamientos cuánticos era la que proporcionaban los estados indefinidos de descripción, la naturaleza dual (ondulatoria y corpuscular) de los fenómenos cuánticos, las leyes de interferencia, y la validez individual de las leyes de conservación.

Nuestro epistemólogo está lejos de simplificar la tarea de acceder a una interpretación realista de la mecánica cuántica. Propone especular en el orden trascendental, pues sólo a partir de las entidades teóricas, a las que se accede originalmente a través de la especulación racional, se puede formular distintas descripciones acerca de lo real. Los átomos, por ejemplo, fueron concebidos inicialmente, a través de la teorización, como realidades trascendentales. Pero Feyerabend (1965) agrega que la tarea medular de la ciencia no se limita a elaborar teorías abstractas o mutuamente inconmensurables. Exige, sobre todo, discutir los supuestos ontológicos de estas teorías y de comparar a éstas a su vez con el material observacional que explican.

\section{Conclusión}

Al destacar la presencia de la metafísica en la ciencia Feyerabend no pretende denostar la ciencia sino demostrar que es falsa la dialéctica que tanto el positivismo lógico como el racionalismo crítico establecen entre ciencia y metafísica. En un sentido positivo, se puede decir que la proliferación teórica impide o evita retomar, a la hora de definir la empresa científica, las dialécticas propias del positivismo lógico o del racionalismo crítico entre ciencia y metafísica.

Se podría contemplar la posibilidad de que se acuse al vienés de cometer en esta formulación de su proliferación teórica una instancia de falacia genética: pues no porque en la metafísica se hayan iniciado ideas que llegaron a ser parte de la ciencia, debe reconocerse el fracaso de la separación entre ciencia y metafísica. O, desde otra perspectiva, no porque en la metafísica se explique la génesis psicológica o accidental de la ciencia se puede dictar la superioridad de aquella sobre ella. Luego Feyerabend no puede juzgar la ciencia actual en razón de su origen mítico o filosófico.

Ahora, Feyerabend no concluye la unidad intrínseca entre ciencia y metafísica $\mathrm{y}$, lo que es lo mismo, la abolición de todo criterio de demarcación argumentando que aquella constituye el reservorio imaginativo a partir del cual se originan las teorías científicas. El vienés (1963a, pp. 321-322) no defiende a la metafísica como un mero dispositivo psicológico que interviene en la invención de nuevos modelos 
explicativos, tal como ya lo supo hacer Karl Popper. Dando un paso más, postula la conveniencia metodológica de que la metafísica sea parte de lo que sus interlocutores reconocen como quehacer propiamente científico. Sin abandonar nunca el carácter irónico de esta crítica da cuenta de las ventajas metodológicas que se siguen de la integración de la metafísica en la práctica científica, a saber, argumenta que sin ella la ciencia no podría prevenir los dogmatismos que obstaculizan el progreso científico, aumentar su contenido empírico y, finalmente, superar el carácter instrumental que caracteriza a muchas de las teorías científicas.

En el pluralismo teórico Feyerabend esboza un modelo de ciencia donde la metafísica se presenta no como una disciplina autónoma respecto a la ciencia sino como las distintas cosmovisiones que atraviesan y definen el entero curso del quehacer científico. Pero no se limita a destacar la presencia ineludible de la metafísica en la ciencia sino que da cuenta, sobre todo, el papel positivo que efectúa ésta en la ciencia. En sus habituales argumentos por reducción al absurdo demuestra que la ciencia -tal como la concibe el positivismo lógico y el racionalismo crítico- debe asumir la reflexión metafísica en orden a que las teorías no degeneren en dogmas que entorpecen el progreso científico, alcancen el ideal de aumento de contenido empírico y se conviertan en un conocimiento auténtico y real del mundo.

Ante la posibilidad de que una teoría seleccione únicamente la evidencia que la confirma, deviniendo así en un dogmatismo, Feyerabend destaca la necesidad de introducir nuevas teorías que provean nueva evidencia o experimentos cruciales capaces de cuestionar o refutar a la teoría imperante. Pero estas teorías no pueden ser inferidas de la evidencia observacional de la teoría vigente. Esta situación da lugar a Feyerabend a reivindicar la necesidad de la metafísica, esta vez entendida como fuente no observacional de las especulaciones que dan origen a las nuevas teorías.

Por otro lado apunta que el progreso científico - tal como es definido por el positivismo lógico y el racionalismo crítico- exige que la filosofía no se limite a reflejar o clarificar los desarrollos de la ciencia sino que juegue un rol activo y crítico en la ciencia construyendo visiones del mundo alternativas a las imperantes.

Finalmente, el vienés defiende la metafísica en cuanto que por ésta la ciencia puede explicar y dar cuenta del mundo. Si se la excluye del cuerpo científico de conocimientos la ciencia deviene en un esquematismo predictivo de fenómenos carentes de explicación y sentido. Feyerabend sostiene, e ilustra concretamente con el problema de la interpretación de la física cuántica. Así a la tarea medular de la ciencia de formular teorías mutuamente inconmensurables añade la exigencia de discutir los supuestos ontológicos de las teorías y de comparar, a su vez, éstos con la experiencia. En contraposición con la filosofía analítica Feyerabend denuncia la urgencia de rescatar la filosofía tradicional, es decir, la necesidad de restablecerla como posibilidad de discutir los problemas fundamentales del quehacer científico. 
En síntesis, la proliferación teórica constituyó una ocasión para defender metodológicamente la metafísica como una dimensión integrada en el cuerpo y la práctica del conocimiento científico.

\section{Referencias bibliográficas}

Bartley, W. (1964). "Rationality Versus the Theory of Rationality". The Critical Approach to Science and Philosophy. Bunge M. (ed.). London: The Free Press of Glencoe, Collier-MacMillan Limited: 3-31.

BIRD, A. (2002). "Kuhn's wrong Turn." Studies in History and Philosophy of Science 33: 443-463.

BoHr, N. (1928). "The quantum postulate and the recent developments of atomic theory". Nature 121: 580-590.

BoyD, R. (1992). "Constructivism, Realism and Philosophical Method, Inference Explanation, and other Frustrations". Essays in the Philosophy of Science, J. Earman (ed.). Berkeley, University of California Press: 131- 198.

Caneva, K. (2000). "Possible Kuhns in the History of Science: Anomalies of Incommensurable Paradigms." Studies in History and Philosophy of Science 31: $87-124$.

Carnap, R. (1978). "La Superación de la Metafísica mediante el Análisis Lógico del Lenguaje." El Positivismo Lógico. Ayer A. (Comp.) México, Fondo de Cultura Económica: 66-87.

Couvalis, G. (1988). "Discussion: Feyerabend and Laymon on Brownian Motion". Philosophy of Science 55: 415-421.

Couvalis, G. (1999). "Review Symposia: Radical Fallibilism vs Conceptual Analysis: The Significance of Feyerabend's Philosophy of Science." Metascience 8: 206-216.

FArrell, R. (2003). Feyerabend and Scientific Values. Tightrope-Walking Rationality, Kluwer Academic Publishers, Netherlands.

FArRell, R. (2000). "Will the Popperian Feyerabend Please Step Forward: Pluralistic, Popperian Themes in the Philosophy of Paul Feyerabend." International Studies in the Philosophy of Science 14: 257-266.

Feyerabend, P. (1958a). "Complementarity". Proceedings of Aristotelian Society, Suppl. Vol. 32: 75-104.

FEYERABEND, P. (1958b). "An Attempt at a Realistic Interpretation of Experience." Proceedings of the Aristotelian Society 58: 143-170.

FEYERABEND, P. (1958c). "Review of Mathematical Foundations of QuantumMechanics. By John von Neumann. British Journal for the Philosophy of Science 8: 343- 347. 
FEYERABEND, P. (1958/1981a). "An attempt at a realistic interpretation of experience". Realism, rationalism and scientific method, Philosophical Papers Volume 1. Cambridge, Cambridge University Press: 17-36.

FEyerabend, P. (1958/1981b). "Reichenbach's Interpretation of Quantum Mechanics." Realism, rationalism and scientific method, Philosophical Papers Volume 1. Cambridge, Cambridge University Press: 236-246.

Feyerabend, P. (1959b). "Comments on Sellars. The Language of Theories". Current Issues in the Philosophy of Science. Symposia of Scientists and Philosophers. Proceedings of Section L of the American Association for the Advancement of Science. H. Feigl- G. Maxwell (eds.), New York, Holt, Rinehart- Winston.

Feyerabend, P. (1960a). "Professor Bohm 's Philosophy of Nature. Review of Causality and Chance in Modern Physics. By David Bohm." British Journal for the Philosophy of Science 10: 321- 338.

Feyerabend, P. (1960/1981a). "On the Interpretation of scientific theories". Realism, rationalism and scientific method, Philosophical Papers Volume 1. Cambridge, Cambridge University Press: 37-43.

Feyerabend, P. (1960/1981b). "Professor Bohm's Philosophy of Nature". Realism, rationalism and scientific method. Philosophical Papers Volume 1. Cambridge, Cambridge University Press: 219-235.

Feyerabend, P. (1960/1999). "The Problem of the Existence of Theoretical Entities". Paul K. Feyerabend: Knowledge, Science and Relativism, Philosophical Papers Volume 3. John Preston (ed.). Cambridge, Cambridge University Press: 16-49.

FEyerabend, P. (1960/2005). "El problema de la existencia de las entidades teóricas." Scientiae Studia 3: 277-312.

Feyerabend, P. (1961a). "Review of Metascientific Queries and Causality. By Mario Bunge." Philosophical Review 70: 396-405.

FEYERABEND, P. (1961b). "Review of An Introduction to the Logic of the Sciences. By Rom Harré." British Journal for the Philosophy of Science 12: 245-250.

Feyerabend, P. (1961/1995). "Two Letters of Paul Feyerabend to Thomas S. Kuhn on a Draft of The Stucture of Scientific Revolutions". Hoyningen-Huene P. (ed.). Studies in History and Philosophy of Science 26: 353-387.

Feyerabend, P. (1961/1999). "Knowledge without foundation." Paul K. Feyerabend: Knowledge, Science and Relativism, Philosophical Papers Volume 3, John Preston (ed.). Cambridge, Cambridge University Press: 50-77.

Feyerabend, P. (1962). "Problems of Microphysics." Frontiers of Science and Philosophy: University of Pittsburgh Series in the Philosophy of Science Volume 1. Colodny R. (ed.). Pittsburgh, University of Pittsburgh Press: 189-283. FEYERABEND, P. (1962/1981a). "Hidden variables and the argument of Einstein, 
Podolsky and Rosen." Realism, rationalism and scientific method, Philosophical Papers Volume 1. Cambridge, Cambridge University Press: 298342.

Feyerabend, P. (1962/1981b). "Explanation, Reduction and Empiricism." Realism, rationalism and scientific method, Philosophical Papers Volume 1. Cambridge, Cambridge University Press: 44-96.

FEYERABEND, P. (1962/1989). Limites de la ciencia. Explicación, reducción y empirismo. Barcelona, Paidós.

Feyerabend, P. (1963). "Review of Erkenntnislehre. By Victor Kraft." British Journal for the Philosophy of Science 13: 319-323.

FEYERABEND, P. (1963/1999). "How to be a good empiricist: a plea for tolerance in matters epistemological". Paul K. Feyerabend: Knowledge, Science and Relativism. Philosophical Papers Volume 3, John Preston (ed.). Cambridge, Cambridge University Press: 78-103.

Feyerabend, P. (1963/2013). "Carta a Jack J. C. Smart”. Filosofia Natural. Buenos Aires, Debate: $284-294$.

FEYeRABEND, P. (1963/1981). "Materialism and the mind-body problem." Realism, rationalism and scientific method, Philosophical Papers Volume 1. Cambridge, Cambridge University Press: 161-175.

Feyerabend, P. (1964a). "Review of Scientific Change." Crombie A. (ed.). The British Journal for the Philosophy of Science 15: 244-254.

Feyerabend, P. (1964b). "Review of The Concept of the Positron. A Philosophical Analysis. By N. R. Hanson." The Philosophical Review 73: 64-266.

Feyerabend, P. (1964c). "A Note on the Problem of Induction." Journal of Philosophy 61: 349-353.

Feyerabend, P. (1964/1981). "Realism and Instrumentalism: Comments on the Logic of Factual Support." Realism, rationalism and scientific method, Philosophical Papers Volume 1. Cambridge, Cambridge University Press: 176202.

Feyerabend, P. (1965). "Problems of Empiricism." Beyond the Edge of Certainty. Essays in Contemporary Science and Philosophy. Colodny R. (ed.). Pittsburg, CPS Publications in the Philosophy of Science: 145-260.

Feyerabend, P. (1965/1981a). "On the "Meaning" of Scientific Terms." Realism, rationalism and scientific method, Philosophical Papers Volume 1. Cambridge, Cambridge University Press: 97-103.

Feyerabend, P. (1965/1981b). "Reply to Criticism. Comments on Smart, Sellars and Putnam." en Realism, rationalism and scientific method, Philosophical Papers Volume 1. Cambridge, Cambridge University Press: 104-131.

Feyerabend, P. (1966). "Dialectical Materialism and the Quantum Theory." Slavic Review 25: 414-417. 
Feyerabend, P. (1967). "Review of Law and Psychology in Conflict." By J. Marshall. Inquiry 10: 114-120.

FEYERABEND, P. (1968/1981). "Niels Bhor's world view". Realism, rationalism and scientific method, Philosophical Papers Volume 1. Cambridge, Cambridge University Press: 247-297.

Feyerabend, P. (1969). "On a Recent Critique of Complementarity: Part II." Philosophy of Science 36: 82-105.

Feyerabend, P. (1968/1999). "Outline of Pluralistic Theory of Knowledge and Action". Paul K. Feyerabend: Knowledge, Science and Relativism, Philosophical Papers Volume 3, John Preston (ed.). Cambridge, Cambridge University Press: 104-111.

FEYERABEND, P. (1969/1981). "Linguistic arguments and scientific method". Realism, rationalism and scientific method, Philosophical papers vol. I. Cambridge, Cambridge University Press: 146-160.

Feyerabend, P. (1970/1981a). "Classical Empiricism". Problems of Empiricism. Philosophical Papers Volume 2. Cambridge, Cambridge University Press: 3451.

Feyerabend, P. (1970/1981b). "Two Models of Epistemic Change: Mill and Hegel". Problems of Empiricism. Philosophical Papers Volume 2. Cambridge, Cambridge University Press: 65-79.

Feyerabend, P. (1970/1981c). "Consolations for the Specialist". Problems of Empiricism. Philosophical Papers Volume 2. Cambridge, Cambridge University Press: 131-167.

Feyerabend, P. (1970/1989). Contra el Método. Esquema de una Teoría Anarquista del Conocimiento. Barcelona, Ariel.

Feyerabend, P. (1972/1999). "On the Limited Validity of Methodological Rules." Paul K. Feyerabend: Knowledge, Science and Relativism, Philosophical Papers Volume 3, John Preston (ed.). Cambridge, Cambridge University Press: 138-180.

Feyerabend, P. (1975/1992). Tratado contra el Método. Esquema de una Teoría Anarquista del Conocimiento. Madrid, Tecnos.

Feyerabend, P. (1978/1982). La Ciencia en una Sociedad Libre. Madrid, Veintiuno Editores s.a.

Feyerabend, P. (1978/1993). ¿Por qué no Platón? Madrid, Tecnos.

Feyerabend, P. (1980/1999). "Democracy, Elitism and Scientific Method". Paul K. Feyerabend: Knowledge, Science and Relativism, Philosophical Papers Volume 3, John Preston (ed.). Cambridge, Cambridge University Press: 212226.

Feyerabend, P. (1981a). "Introduction: Scientific Realism and Philosophical Realism." Realism, rationalism and scientific method, Philosophical Papers Volume 1. Cambridge, Cambridge University Press: 3-16. 
Feyerabend, P. (1981b). "The Methodology of Scientific Research Programmes". Problems of Empiricism. Philosophical Papers Volume 2. Cambridge, Cambridge University Press: 202-230.

FEYERABEND, P. (1981c). "More Clothes from the Emperor's Bargain basement: a Review of Laudan's Progress and its Problems". Problems of Empiricism. Philosophical Papers Volume 2. Cambridge, Cambridge University Press: 231246.

FeyerABEND, P. (1989). "Realism and the Historicity of Knowledge." Journal of Philosophy 86: 393-406.

Feyerabend, P. (1989/2000). Diálogos sobre el Método. $2^{\mathrm{a}}$ ed. Madrid, Cátedra.

Feyerabend, P. (1991a). Three Dialogues on Knowledge. Cambridge, Basil Blackwell.

Feyerabend, P. (1991b). Diálogos sobre el conocimiento. Madrid: Cátedra.

Feyerabend, P. (1991/2003). Provocaciones Filosóficas. Madrid, Editorial Biblioteca Nueva.

Feyerabend, P. (1993/2008). Against Method. Third Edition. London, Verso.

Feyerabend, P. (1996/1999). Ambigüedad y Armonía. Barcelona, Paidós.

Gattei, S. (2002). "The Ethical Nature of Karl Popper's Solution to the Problem of Rationality". Philosophy of the Social Sciences 32: 240-266.

GentiLE, N. (2007). "El camino de Feyerabend: crítica, proliferación y realismo", Filosofía Unisinos 8: 109-127.

HowarD D. (2004) "Who Invented the "Copenhagen Interpretation"? A Study in Mythology". Philosophy of Science 71: 669-682.

Hoyningen-Huene, P. (1993). Reconstructing Scientific Revolutions. The Philosophy of Science of Thomas S. Kuhn. Chicago, The University of Chicago Press, Chicago.

Hoyningen-Huene, P. (1997). "Paul K Feyerabend." Journal for General of Philosophy of Science 28: 1-18.

Hoyningen-Huene, P. (2000a). "Paul K. Feyerabend. An Obituary." The Worst Enemy of Science? Essays in memory of Paul Feyerabend. J. Preston, G. Munévar and D. Lamb (eds.). New York, Oxford University Press: 3-15.

Hoyningen-Huene, P. (2000b). "Paul K. Feyerabend and Thomas Kuhn." The Worst Enemy of Science? Essays in memory of Paul Feyerabend. J. Preston, G. Munévar and D. Lamb (eds.). New York, Oxford University Press: 102-114.

Laudan, L. (1996). Beyond Positivism and Relativism: Theory, Method and Evidence. Boulder, Westview Press.

LAYMON R. (1977). "Feyerabend, Brownian Motion, and the Hiddenness of Refuting Facts". Philosophy of Science 44: 225-247.

Lloyd E., (1996). "The Anachronistic Anarchist.” Philosophical Studies 81: 247261. 
Moore H. (1972). "Dewey and the Philosophy of Science." Man World 5: 158-168. Munévar, G. (1999). "Reviews Symposia: Radical Fallibilism vs Conceptual Analysis: The Significance of Feyerabend's Philosophy of Science". Metascience 8: 216-226.

MunÉvar, G. (2006). Variaciones filosóficas sobre temas de Feyerabend. Germán Guerrero Pino (Comp.). Caracas, Programa editorial Universidad del Valle.

OBERHEIM E. (2005). "On the historical origins of the contemporary notion of incommensurability: Paul Feyerabend's assault on conceptual conservativism". Studies in the History and Philosophy of Science 36: 363-390.

Oberheim E., (2006), Feyerabend's Philosophy. Quellen Und Studien Zur Philosophie. Berlín, Walter de Gruyter.

Oberheim E., Hoyningen-Huene P., (1999). "Reviews Symposia: Radical Fallibilism vs Conceptual Analysis: The Significance of Feyerabend's Philosophy of Science." Metascience 8: 226-233.

Oberheim E., Hoyningen-Huene P., (2000). "Essay Review of John Preston's Feyerabend: Philosophy, Science and Society (Cambridge Polity, 1997)", Studies in History and Philosophy of Science 31: 363-375.

Popper, K. (1962). La lógica de la investigación científica. Madrid, Técnos.

Popper, K. (1963). Conjectures and Refutations, $1^{\text {st }}$ ed. Routledge, London.

Popper, K. (1966). The Open Society and its Enemies: Vol. II. The High Tide of

Prophecy: Hegel, Marx, and the aftermath. 5th. ed. Princeton: Princeton University Press.

Popper, K. (1972). Conjectures and Refutations: The Growth of Scientific Knowledge. $4^{\text {th }}$ ed. London: Routledge.

Popper, K. (1980). The Logic of Scientific Discovery. 4th. ed. London, Routledge. Popper, K. (1985). Realismo y el objetivo de la ciencia. Madrid, Tecnos.

Preston, J., (1997a). Feyerabend. Philosophy, Science and Society. Oxford, Blackwell.

Preston, J. (1997b). "Feyerabend's Retreat from Realism." Philosophy of Science 64: 421-431.

Preston, J. (1999). Reviews Symposia: Radical Fallibilism vs Conceptual Analysis: The Significance of Feyerabend's Philosophy of Science." Metascience 8: 233-243.

Preston, J. (2009). "Paul Feyerabend." Stanford Encyclopedia of Philosophy. Winter 2012 Edition. . Zalta E. (ed). En línea: http:/plato.standford.edu/archives/win2012/entries/feyerabend/, consultado el 15/6/2007.

Putnam, H. (1981). Reason, Truth and History. Cambridge, Cambridge University Press.

RAdnitzky, G., BARTley W. (eds.) (1987). (eds.). Evolutionary Epistemology, Rationality, and the Sociology of Knowledge. Le Salle: Open Court. 
Reaven, S. (2000). “Time Well Spent: On Paul Feyerabend's Autobiography.” The Worst Enemy of Science? Essays in memory of Paul Feyerabend. J. Preston, G. Munévar and D. Lamb (eds.). New York, Oxford University Press: 16- 27.

SANKeY, H. (1994a). The Incommensurability Thesis. Aldershot, Avebury.

SANKEY, H. (1997a). Rationality, Relativism and Incommensurability. Aldershot,Ashgate.

SANKEy, H. (1997b). "Incommensurability: The Current State of Play." Theoria 12: 425-445.

SANKEY, H. (1998). "Taxonomic Incommensurability." International Studies in the Philosophy of Science 12: 7-16.

Sirtres, D., Oberheim, E. (2006). "Einstein, Entropy and Anomalies." Albert Einstein Century Inernational Conference. Alimi J., Füzfa A. (eds.). American Institute of Physics, Ber.

Van Fraassen B. (1984). "To Save the Phenomena." Scientific Realism. J. Leplin (ed.). Berkeley, University of California Press: 250-259.

Worrall, J. (1978), "Is the Empirical Content of a Theory Dependent on its Rivals?”. Acta Philosophica Fennica 30: 298-310.

María Teresa Gargiulo de Vazquéz

Universidad de Congreso - Conicet (Argentina)

gargiulomteresa@gmail.com 